\title{
Equilibrium Default Cycles
}

\section{Natalia Kovrijnykh and Balázs Szentes}

University of Chicago

\begin{abstract}
This paper analyzes Markov equilibria in a model of strategic lending in which (i) agents cannot commit to long-term contracts, (ii) contracts are incomplete, and (iii) incumbent lenders can coordinate their actions. Default cycles occur endogenously over time along every equilibrium path. After a sequence of bad shocks, the borrower in a competitive market accumulates debt so large that the incumbent lenders exercise monopoly power. Even though the incumbents could maintain this power forever, they find it profitable to let the borrower regain access to the competitive market after a sequence of good shocks. Equilibria are computed numerically, and their attributes are qualitatively consistent with numerous known empirical facts on sovereign lending. In addition, the model predicts that a borrower who accumulates debt overhang will regain access to the competitive credit market only after good shocks. This prediction is shown to be consistent with data on emerging market economies.
\end{abstract}

\section{Introduction}

Sovereign countries often accumulate debts so large that they decide to cease their required payments and go into default. As a result, such countries typically lose access to credit markets. After some time, often more than a decade, lenders renegotiate the size of the debt with the

We have benefited from discussions with Fernando Alvarez, Harold Cole, Jonathan Eaton, Raquel Fernandez, Gita Gopinath, Bengt Holmstrom, Hugo Hopenhayn, John Leahy, Robert Lucas, Rody Manuelli, Casey Mulligan, Andy Neumeyer, Marco Ottaviani, Phil Reny, Robert Shimer, and Nancy Stokey. We are grateful for comments by seminar participants at Massachusetts Institute of Technology, Northwestern University, New York University, University of Chicago, University of Rochester, University of Southern California, the 2005 Midwest Macroeconomics meetings, and the 2005 Society for Economic Dynamics meetings. Financial support from the National Science Foundation is gratefully acknowledged.

[ Journal of Political Economy, 2007, vol. 115, no. 3]

(C) 2007 by The University of Chicago. All rights reserved. 0022-3808/2007/11503-0002\$10.00 
TABLE 1

Selected Government Defaults and Reschedulings of Privately Held Bonds AND LOANS, 1820-2003

\begin{tabular}{lccccccc}
\hline \hline & $1824-$ & $1867-$ & $1890-$ & $1911-$ & $1931-$ & $1976-$ & $1998-$ \\
& 1834 & 1882 & 1900 & 1921 & 1940 & 1989 & 2003 \\
\hline Argentina & 1830 & & 1890 & 1915 & 1930 s & 1982 & 2001 \\
Brazil & 1826 & & 1898 & 1914 & 1931 & 1983 & \\
Chile & 1826 & 1880 & & & 1931 & 1983 & \\
Costa Rica & 1827 & 1874 & 1895 & & 1937 & 1983 & \\
Ecuador & 1832 & 1868 & & 1911,1914 & 1931 & 1982 & 1999 \\
Mexico & 1827 & 1867 & & 1914 & & 1982 & \\
Nicaragua & 1828 & & 1894 & 1911 & 1932 & 1980 & \\
Paraguay & 1827 & 1874 & 1892 & 1920 & 1932 & 1986 & \\
Peru & 1826 & 1876 & & & 1931 & 1978,1983 & \\
Uruguay & & 1876 & 1891 & 1915 & 1933 & 1983 & 2003 \\
Venezuela & 1832 & 1878 & 1892,1898 & & & 1982 & \\
\hline
\end{tabular}

Source.-Sturzenegger and Zettelmeyer (2005).

offending country, and, now in good standing, the country regains credit market access. But the story does not end there. These countries accumulate large debts once again and default on them once again, and the cycle repeats. Such cycles are illustrated in table 1, which displays the years of defaults of several Latin American countries.

The current literature on sovereign lending does not provide a satisfactory explanation of these phenomena. The goal of this paper is to build a theory that explains these cycles and makes the time of exclusion from the credit market endogenous and potentially long. ${ }^{1}$

Our explanation of default cycles is as follows. A borrower, with a small amount of debt, obtains capital from some lender in a competitive credit market. Random shocks, good and bad, affect the success of the borrower's project. Following bad shocks, the borrower typically borrows more, and following good shocks, she typically pays down her debt. All the while, the presence of the competitive credit market keeps the incumbent lender's expected future profits equal to the borrower's debt. Eventually, however, and with probability one, sufficiently many successive bad shocks lead the borrower to accumulate more debt than the maximum surplus that any lender can extract from her. The borrower is then said to be in a state of debt overhang.

When the borrower is in debt overhang and because old debt is senior to new debt, no new lender from the competitive fringe will lend to her. Consequently, this marks the beginning of the period of time during which the borrower is unable to participate in the competitive credit market. On the other hand, the incumbent lender, who now exercises

\footnotetext{
${ }^{1}$ In their seminal paper, Eaton and Gersovitz (1981) assume that the penalty for default is a permanent exclusion from future credit. They say that an important elaboration would be to make the time of exclusion endogenous.
} 
a degree of market power over the borrower, remains willing to lend to the borrower in order to salvage a portion of what he is owed. In fact, if the lender's sunk losses are ignored, his market power permits him to earn positive expected future profits from the borrower.

The central purpose of our work is to provide an explanation of how and why the borrower inevitably regains access to the competitive credit market, especially in light of the fact that the incumbent lender has the ability to keep the borrower in a state of debt overhang and continue to exercise market power. Why then would the incumbent permit the borrower to regain access to the competitive credit market? The answer, of course, is that the incumbent lender does so because it increases his profits. Indeed, even in a state of debt overhang, the borrower might have high income following a sequence of good shocks. If the incumbent lender had full commitment power, he could extract this income through a lump-sum payment in exchange for a commitment to provide the borrower with efficient investments in all future periods. Unfortunately, the incumbent cannot commit in this way. However, the incumbent can come closest to this by providing the borrower with access to the competitive credit market and, with it, access to more efficient investment decisions. Thus, when the borrower has sufficiently high income, it can be optimal for the incumbent to offer to reduce the borrower's debt to a level at which the borrower regains access to the competitive credit market in exchange for the borrower's income today. The efficiency of the credit market makes this attractive for the borrower.

Regarding the length of time spent in debt overhang, this will depend on several factors, including the general productivity of the project, as well as the distribution of productivity shocks. In particular, a borrower in debt overhang will remain in debt overhang after a bad shock. Only after sufficiently many good shocks will a borrower have enough income to make it worthwhile for the lender to accept that income today for a debt reduction tomorrow that is large enough to eliminate the state of debt overhang. Once the borrower regains access to the competitive credit market, the entire process repeats. These default cycles are an equilibrium phenomenon.

As should be clear from the above explanation, the occurrence of debt overhang is a statistical inevitability. The interesting and novel part of our explanation lies in the borrower's return from debt overhang to the competitive credit market. In our model, the return to the competitive credit market, while also inevitable, is not merely a statistical phenomenon. It is instead an endogenously determined property of equilibrium behavior.

It is worthwhile to contrast our approach with that of much of the literature. The majority of the literature on debt renegotiation assumes that if the borrower is in a state of debt overhang, the parties engage 
in bilateral bargaining to reduce debt (see, e.g., Bulow and Rogoff 1989; Ozler 1989; Fernandez and Rosenthal 1990; Yue 2005). Further, in the bargaining models employed, there is no delay in reaching an agreement. Consequently, debt reduction is immediate. ${ }^{2}$ In contrast, and as explained above, in our model, the time elapsed from the onset of debt overhang to a return to the competitive market is endogenous and potentially long.

The formal model we present is a stochastic dynamic game involving one borrower and two lenders. We study the set of Markov equilibria. In addition to proving that all such equilibria involve default cycles, we identify two sources of inefficiency. When the incumbent lender has monopoly power, he invests less than the socially optimal amount. The reason is that the income is controlled by the borrower, and the lender does not take into account the borrower's payoff when making decisions. On the other hand, if the borrower has enough liquidity and small debt, she overinvests, because overinvesting can decrease the probability of a state of debt overhang in the future.

To investigate time-series properties of the model, we numerically compute an equilibrium and simulate it. Our computational results are qualitatively consistent with many empirical regularities observed in emerging market economies. We show that there is a negative relationship between the level of debt and investment. We find that investment and income are lower in states of debt overhang. Our simulations predict a negative correlation between the borrower's income and the country interest rate. We also find a negative relationship between investment and the country interest rate. We discuss empirical evidence related to our findings in detail in Section VII. Another prediction of our model is that debt reductions occur after a sequence of good productivity shocks. We provide empirical evidence that supports this finding.

Related literature.-Our model has many features similar to those analyzed in the corporate debt literature. In particular, agents are risk neutral, and the motive for borrowing is that the borrower needs to invest in a stochastic production technology. On the other hand, related papers on corporate lending usually analyze ex ante optimal contracts. These papers implicitly assume that contracts cannot be renegotiated; that is, agents can commit to multiperiod contracts. ${ }^{3}$ Instead, we analyze Markov equilibria in a game in which new contracts are offered in every period and agents cannot commit to long-term contracts. To illustrate the differences between this literature and our paper in terms of conclusions, we review a few of these papers.

\footnotetext{
${ }^{2}$ Some papers make time spent outside the credit market exogenously long. Examples of such papers are Cole, Dow, and English (1995), Arellano (2005), and Yue (2005).

${ }^{3}$ Commitment in this literature is often limited, so that contracts must be subject to participation constraints in each period.
} 
Thomas and Worrall (1994) and Albuquerque and Hopenhayn (2004) study an environment very similar to ours. The main difference is that there is only a single lender. ${ }^{4}$ The ex ante optimal contract has the following features. The value to the borrower increases and the value to the lender decreases over time. The reason is that the borrower's participation constraint is easier to satisfy if payments are delayed. Furthermore, the amount of investment increases over time, often converging to the socially optimal level. Our predictions are quite different. Neither the agents' values nor investment depends on time in our equilibria. The reason is that in our model contracts are incomplete and we restrict our attention to Markov equilibria.

Clementi and Hopenhayn (2006) also analyze lending contracts with limited commitment under the assumption that the lender does not observe either the use of funds or the output. The ex ante optimal contracts have the following feature. There are two absorbing states: after some time, either the project is liquidated or only the first-best investment is made and the lender has no claim on the borrower. Liquidation follows a sequence of bad shocks. A sequence of good shocks results in an increasing path for the borrower's value, eventually reaching the first-best social surplus. In sharp contrast with this result, there are no absorbing states in our equilibria; the economy keeps switching between the competitive and the monopoly regimes. Furthermore, investment is always inefficient.

Another paper on ex ante optimal debt contracts is Atkeson (1991). In his model, the lenders do not observe whether the borrower invests or consumes borrowed funds. To provide proper ex ante incentives to the borrower, the optimal contract specifies a fall in consumption and investment for the lowest realizations of output. Our model produces a similar result. If the borrower's income is small and the debt is large, investment is inefficiently small. However, while in Atkeson's model incentives cause this problem, in our model the lender's monopoly power is to blame.

In contrast to our model, the majority of the literature on sovereign lending uses consumption smoothing as a motive for borrowing (see, e.g., Eaton and Gersovitz 1981; Atkeson 1991; Calvo and Kaminsky 1991; Kletzer and Wright 2000; Yue 2005). On the other hand, many papers, like ours, analyze Markov equilibria in the presence of competitive credit markets instead of characterizing optimal contracts.

Most papers on sovereign debt focus mostly on the incentives and welfare of the borrower, whereas the creditors only play passive roles.

\footnotetext{
${ }^{4}$ In Albuquerque and Hopenhayn (2004), there are many competing lenders, but they only force the incumbent lender to earn zero profit ex ante and play no strategic role otherwise.
} 
This paper shifts the focus toward the lenders. A key feature of our model is the dynamics of competition among the lenders resulting from stochastic productivity shocks. This feature can be crucial in analyzing debt overhangs, debt rollovers, and buybacks. A central question of the literature on sovereign lending is whether debt reductions are socially beneficial and whether the borrower or the lender collects the rents from them. Below, we briefly describe the debate on these issues and the contribution of this paper to the debate.

Sachs $(1988,1989,1990)$ argues in favor of debt reductions. He claims that debt burden decreases domestic investment, impedes growth, and aggravates economical and political instability. Krugman (1988b) claims that debt reduction generally benefits both the debtor and the creditors if the debtor is on the wrong side of the "debt relief Laffer curve"that is, if the nominal debt is so high that reducing it actually increases the expected repayment. Krugman (1988a) finds that if the debtor can affect output through a costly effort, the creditor might find it profitable to forgive part of the debt to increase the likelihood that the country will repay the rest. Froot (1989) argues that when a country is liquidity constrained, the creditors should combine debt reduction with new lending in order to stimulate investment, thereby increasing potential future repayments. Calvo and Kaminsky (1991) study a model in which debt reduction is a feature of the optimal contract as a means to improve consumption smoothing.

Bulow and Rogoff (1988), on the other hand, claim that open-market buybacks are likely to be a poor deal for a debtor country that faces debt overhang because the country simply uses its scarce resources to subsidize the creditors. The reason is that a buyback reduces the face value of the debt but the price of the remaining claims rises. Hence, the actual market value of outstanding debt changes little, reflecting low market expectations about the country's capacity to repay debt. The main criticism of Bulow and Rogoff's study is that they do not model inefficiencies associated with debt overhang, such as investment disincentives, limits on future borrowing, and loss of access to credit markets. ${ }^{5}$ However, in another paper, Bulow and Rogoff (1991) argue that even if buybacks stimulate domestic investment, creditors will fully capture the efficiency gain from them.

Fernandez and Rosenthal (1990) present a model in which only the lenders benefit from debt reductions. In their equilibria, if the borrower cannot service her debt, the lenders offer a deal that keeps the borrower indifferent between accepting the deal and defaulting. Since the borrower accepts the deal in equilibrium, all efficiency gains from debt reduction go to the lenders.

${ }^{5}$ See the discussion in Bulow and Rogoff (1988) and Sachs (1988). 
This paper's contribution to the debate is the following. In a state of debt overhang it is socially efficient to reduce the debt instead of letting the borrower go to autarky because, despite the debt overhang, it remains worthwhile to invest in the borrower's production technology. On the one hand, like Bulow and Rogoff $(1988,1991)$ and Fernandez and Rosenthal (1990), we find that only the lenders benefit from buybacks ex post. ${ }^{6}$ The borrower is no better off accepting a debt reduction than refusing it. On the other hand, if debt buybacks are possible, the lenders rationally anticipate that the borrower will not default once debt accumulates. This allows the lenders to recover at least part of their investments. Lenders offer contracts in the credit market that reflect these expectations. Since the credit market is competitive to start with, the borrower then extracts all the ex ante efficiency gain from buybacks. Our arguments emphasize that it is insufficient to analyze environments in which the borrower is already in a state of debt overhang when one evaluates the welfare implications of debt reductions and buybacks.

\section{The Model}

There are three risk-neutral agents: a borrower and two lenders. Time is discrete, and agents discount the future according to the discount factor $\beta$.

\section{A. Production and Preferences}

The borrower has a stochastic technology to transform capital goods into consumption goods. If the amount of capital investment is $K$, then the borrower's income in the next period, in terms of consumption goods, is $F(K)=s f(K)$, where $s$ is the realization of a random shock. The function $f$ is strictly increasing and strictly concave and satisfies the Inada conditions. The shock is distributed according to the cumulative distribution function $G$ and supported on $[0,1]$. Capital completely depreciates every period.

The lenders can instantaneously transform one unit of capital good into one unit of consumption good and vice versa. This means that the lenders are indifferent between the two goods. ${ }^{7}$ The lenders have enough capital to invest in production in every period. Each agent's

\footnotetext{
${ }^{6}$ It is important to distinguish the buyback mechanism used in this paper from other mechanisms. Bulow and Rogoff $(1988,1991)$ consider open-market buybacks, where the face value of debt is reduced by purchasing the debt at a discount. In our model, a buyback is a reduction in the market value of debt. This is the type of buyback implemented, e.g., by letting highly indebted countries swap their debts for Brady bonds in the 1990s.

${ }^{7}$ Having two different goods ensures that the borrower's autarky value is her last-period output. This assumption is not uncommon in the literature; see, e.g., Thomas and Worrall (1994) in the context of foreign direct investment.
} 
goal is to maximize the discounted present value of expected consumption.

\section{B. Timing and Contracts}

No agent can commit to multiperiod contracts. A typical contract consists of three numbers $\left(R, K, D^{\prime}\right): R$ denotes the immediate payment from the borrower to the lender whose contract is accepted, $K(\geq 0)$ is the lender's investment in the production technology, and $D^{\prime}(\geq 0)$ is the next period's debt. More generally, a contract can be a probability mixture of these triples. The simple form of the contract implies that contracts cannot be conditioned on output. ${ }^{8}$

Suppose that, at the beginning of a period, the output realization is $I$ and the debt is $D$. The borrower and both lenders observe $I$ and $D$. Then the lenders simultaneously offer a set of contracts to the borrower. The borrower either chooses a contract from these sets or refuses all of them. If the borrower refuses all contracts, no investment is made, and the next period's debt is $D / \beta{ }^{9}$ If she chooses a contract $\left(R, K, D^{\prime}\right)$, she gives $R$ units of consumption good to the lender who offered this contract, and the lender invests $K$ units of capital in the production technology. ${ }^{10}$ The lender whose contract is accepted also repays the debt $D$ to last period's lender. ${ }^{11}$ The borrower consumes $I-R$ and the new lender consumes $R$. Then the period ends.

Since the borrower is risk neutral, $R$ can always be assumed to be deterministic even though contracts can be random. A contract $(R, K$, $\left.D^{\prime}\right)$ is feasible if $R \leq I$. We call a lender the incumbent at the beginning of a period if the borrower accepted his contract in the previous period. We call the other lender the outsider. The incumbent lender in our model is interpreted as the entire group of lenders to whom an accumulated debt is owed in reality. The outsider lender is interpreted as the entire group of lenders who have no claims on the borrower.

Our assumption that new lenders must fully repay the old debt deserves some discussion. In reality, a borrower can roll over her debt if she can repay some of it and finance the rest of it with new debt contracts. In such a case, the market value of the debt is its face value, and hence it is optimal for new lenders to fully repay old debt. Hence, in this case, our assumption is made without loss. If, on the other hand,

\footnotetext{
${ }^{8}$ This assumption is justified in the literature by pointing out that some shocks are observable but not verifiable.

${ }^{9}$ Here, we follow the convention by assuming that unpaid debt is rolled over according to the world risk-free interest rate, $r$, where $r=(1 / \beta)-1$.

${ }^{10}$ If the borrower accepts a random contract-i.e., a lottery over $\left(R, K, D^{\prime}\right)$ triplesthen the outcome of the lottery is first observed.

${ }^{11}$ One might ask, Why does the borrower not repay $D$, at least partially? The payment $R$ should be viewed as part of the repayment of $D$.
} 
the borrower cannot roll over her debt, our assumption prevents new lenders from ignoring old debt and allowing the borrower to default on it. In other words, our assumption is equivalent to the standard assumption in this literature that old debt is senior to new debt. The argument for debt seniority that is closest to the spirit of our model was first spelled out in Fama and Miller (1972). Their reasoning is as follows. If old debt was not senior, the issuance of new claims would lead to a reduction in the expected repayment to the original debt holders. The reason is that if the borrower becomes insolvent, old creditors have to share the recovery value of debt with new ones. Anticipating this, creditors might refuse to lend altogether. This problem is solved if old debts have priority over new ones. In the literature on debt renegotiation and buybacks, every paper maintains this assumption, in one form or in another.

\section{The First-Best Investment}

Since each agent is risk neutral, the optimal (first-best) investment maximizes $\beta \int_{0}^{1} s f(K) d G(s)-K$. The solution, $K_{\mathrm{FB}}$, is defined by the following first-order condition:

$$
\beta f^{\prime}\left(K_{\mathrm{FB}}\right) \int_{0}^{1} s d G(s)=1 .
$$

Let $S_{\mathrm{FB}}(I)$ denote the first-best social surplus if the borrower's income is $I$. That is,

$$
S_{\mathrm{FB}}(I)=I+\frac{-K_{\mathrm{FB}}+\beta f\left(K_{\mathrm{FB}}\right) \int_{0}^{1} s d G(s)}{1-\beta} .
$$

\section{Equilibrium Concept}

We restrict attention to Markov equilibria. To be more specific, we are interested in subgame-perfect equilibria in which the set of contracts offered by a lender depends only on the borrower's income, $I$, the current debt, $D$, and whether the lender is the incumbent or the outsider. The borrower's choice of contract depends only on her income, debt, and the set of contracts offered.

In the next sections, we operate under the assumptions that (i) Markov equilibria exist and (ii) autarky is not a Markov equilibrium. We characterize some properties of all Markov equilibria. These properties then play an important role in the equilibrium existence proof in Appendix $\mathrm{B}$, where we also prove that autarky is indeed not a Markov equilibrium. 


\section{Preliminaries}

Fix a Markov equilibrium and introduce the following notation. Let $W^{L}(I, D)$ and $W^{B}(I, D)$ denote the equilibrium payoffs to the incumbent and to the borrower, respectively, at the beginning of a period if the borrower's income is $I$ and her debt is $D$. We refer to $W^{L}$ and $W^{B}$ as value functions and to the pair $(I, D)$ as a state.

\section{A. Incentives}

Suppose that the borrower's income is $I$ and the debt is $D$. Then she prefers accepting the contract $\left(R, K, D^{\prime}\right)$ to refusing all offered contracts if

$$
I-R+\beta E W^{B}\left(F(K), D^{\prime}\right) \geq I+\beta W^{B}(0, D / \beta) .
$$

The left-hand side is the expected payoff from accepting the contract. ${ }^{12}$ The right-hand side is the borrower's outside option. If she refuses all contracts, she consumes $I$, but since no investment is made, the next period's income is zero and the debt is rolled over according to $1 / \beta$. Furthermore, the contract must satisfy $R \leq I$ to be feasible.

The outsider lender is willing to offer only those contracts under which his expected payoff is large enough to cover the current debt, $D$, that he must pay to the incumbent lender. The following constraint describes these contracts:

$$
R+E\left[-K+\beta W^{L}\left(F(K), D^{\prime}\right)\right] \geq D,
$$

where $R \leq I$. The left-hand side of the inequality is the outsider lender's expected payoff from his relationship with the borrower. The right-hand side is the required payment to the incumbent.

If the outsider lender offers a contract satisfying (3), then it would also be profitable for the incumbent lender to offer the same contract. The reason is that if the incumbent offers this contract and it is accepted, his payoff is the left-hand side of (3); otherwise his payoff is $D$. Therefore, without loss of generality, we assume that the incumbent lender's contract is always the one accepted along the equilibrium path.

\section{B. Debt Overhang}

The debt $D$ may be so high that no feasible contract can satisfy (2) and (3) simultaneously. In such a situation, the outsider lender cannot offer any contract that both guarantees him a nonnegative payoff and is ac-

\footnotetext{
${ }^{12}$ Since contracts can be random, $K$ and $D$ can be random variables. On the left-hand side of eq. (2), the expectation is over the randomness of the contract as well as over the next period's shock.
} 
ceptable to the borrower. However, the incumbent may still be willing to offer a contract even if $D$ cannot be fully recovered. This observation is central to our results. The current debt, $D$, is a sunk cost to the incumbent but limits the outsider's ability to offer contracts.

Let $V^{L}(I)$ denote $\sup _{D} W^{L}(I, D)$. Since $W^{L}(I, D)$ is bounded by the first-best social surplus, $V^{L}(I)$ is finite. If the debt exceeds $V^{L}(I)$, it is so high that the incumbent can never extract full repayment from the borrower in the future. On the other hand, the next proposition shows that if $D<V^{L}(I)$, the incumbent's payoff is exactly $D$. Hence, we say that a borrower with income $I$ and debt $D$ faces debt overhang if $D \geq V^{L}(I)$.

Proposition 1. $W^{L}(I, D)=\min \left\{D, V^{L}(I)\right\}$.

The argument of the proof is as follows. If $D<V^{L}(I)$, the incumbent faces competition from the outsider and cannot offer a contract that the borrower accepts and that generates a payoff higher than $D$. Otherwise the outsider could offer essentially the same contract with a slightly smaller $R$. The borrower would accept this contract, and the incumbent's payoff would be $D$. If $D \geq V^{L}(I)$, the incumbent cannot extract more than $V^{L}(I)$ from the borrower. Therefore, the outsider cannot offer a contract that is acceptable to the borrower and that would make it strictly profitable to repay $D$ to the incumbent. Hence, if $D \geq$ $V^{L}(I)$, the incumbent acts as a monopolist, in which case his payoff is $V^{L}(I)$. We refer to $V^{L}$ as the monopolistic value function of the incumbent lender.

\section{Market Structure}

In what follows, we show that the contracting protocol in our game implies perfect competition if $D<V^{L}(I)$ and monopoly power for the incumbent lender if $D \geq V^{L}(I)$.

If the borrower could offer a contract to the lenders subject to the constraint that the current debt $D$ must be paid to the incumbent lender, her maximization problem would be

$$
\max _{R, K, D^{\prime}} I-R+\beta E W^{B}\left(F(K), D^{\prime}\right)
$$

subject to (3). We show below that if $D<V^{L}(I)$, the contract accepted by the borrower solves this constrained maximization problem. In addition, (3) holds with equality. This means that whenever there is no debt overhang, the lenders are Bertrand competitors.

On the other hand, if $D \geq V^{L}(I)$, we will show that the incumbent lender can give a take-it-or-leave-it offer to the borrower. Thus the contract accepted in equilibrium solves

$$
\max _{R, K, D^{\prime}} R+E\left[-K+\beta W^{L}\left(F(K), D^{\prime}\right)\right]
$$


subject to (2). This implies that whenever the borrower faces debt overhang, the incumbent lender has monopoly power. We refer to the incumbent at a state $(I, D), D \geq V^{L}(I)$, as the monopolist. The following proposition lays this out formally.

Proposition 2. Suppose that the equilibrium contract is $\left(R^{*}\right.$, $\left.K^{*}, D^{*}\right)$ at $(I, D)$. Then the following conditions hold:

a. If $D<V^{L}(I)$, then $\left(R^{*}, K^{*}, D^{*}\right)$ solves (4) subject to (3), and (3) holds with equality.

b. If $D \geq V^{L}(I)$, then $\left(R^{*}, K^{*}, D^{*}\right)$ solves (5) subject to (2).

Proposition 2 suggests that the borrower may want to avoid debt overhang because the incumbent, not the borrower, will make decisions if $D \geq V^{L}(I)$. From the borrower's point of view, these decisions may well be inefficient. We will show that this in fact happens in every equilibrium.

According to proposition 2, the economy is always in one of two regimes. The proposition does not imply, however, that the economy keeps switching between these two regimes. The main result of this paper is that, in fact, it does. Although proposition 2 makes a sharp distinction between the case in which $D \geq V^{L}(I)$ and the case in which $D<V^{L}(I)$, it turns out that the borrower becomes continuously (weakly) worse off as the debt increases because the set of available contracts satisfying equation (3) shrinks continuously as $D$ gets larger.

\section{The Value Functions}

This section characterizes the value functions. First, we describe some properties of the lender's monopolistic value function, $V^{L}$. Then, as a function of $V^{L}$, we fully characterize the value function of the borrower, $W^{B}$. Our strategy is to express all the value functions in terms of $V^{L}$. This will play an important role in establishing the existence of an equilibrium. (See App. B.)

\section{A. The Value Functions of the Incumbent}

The next lemma describes some attributes of the function $V^{L}$.

\section{LEMMA 1.}

a. $V^{L}$ is increasing.

$b$. If $\delta>0$, then $V^{L}(I+\delta)-\delta \leq V^{L}(I)$ for all $I$.

c. $V^{L}$ is concave.

The value to the monopolist incumbent is weakly increasing in the borrower's income because the more income the borrower has, the more surplus can be extracted from her. This shows part $a$. If the bor- 
rower's income is $I$, the incumbent can give $\delta$ units of consumption good to the borrower and then offer the same contract as the one at $I+\delta$. The incumbent's payoff from this contract is $V^{L}(I+\delta)-\delta$. Of course, the lender might be able to offer a contract that provides him with an even higher payoff; hence $V^{L}(I) \geq V^{L}(I+\delta)-\delta$. This proves part $b$. Part $c$ is merely a consequence of the possibility of random contracts.

Next, we characterize the monopolist's capital investment $K_{0}$ when $I=0$. Computing $K_{0}$ is important because, as we will show, the monopolist incumbent invests $K_{0}$ not only at $I=0$ but also at a large range of other income realizations. At the state $(0, D), D \geq V^{L}(0)$, if the lender could ignore the borrower's incentive constraint, (2), his maximization problem would be

$$
\max _{K, D^{\prime}}-K+\beta E W^{L}\left(F(K), D^{\prime}\right)
$$

Proposition 1 implies that the incumbent is (weakly) better off specifying $D^{\prime} \geq V^{L}(f(K))$. That is, the borrower has no access to the competitive market in the next period, no matter what the realization of her income is. Hence, the maximization problem of the lender can be rewritten as

$$
\max _{K}-K+\beta \int_{0}^{1} V^{L}(s f(K)) d G(s) .
$$

The strict concavity of $f$ implies that the maximization problem (6) has a unique solution, $K_{0}$. If autarky is not an equilibrium, that is, when $V^{L}$ is not constant zero, $K_{0}$ is strictly positive and is characterized by the following first-order condition:

$$
1=\beta f^{\prime}\left(K_{0}\right) \int_{0}^{1} V^{L \prime}\left(s f\left(K_{0}\right)\right) s d G(s)
$$

We will show that at $(0, D), D \geq V^{L}(0)$, the equilibrium contract is $(0$, $\left.K_{0}, D^{\prime}\right)$, where $D^{\prime} \geq V^{L}\left(f\left(K_{0}\right)\right)$.

\section{B. The Value Functions of the Borrower}

First we show that if $D \geq V^{L}(I)$, then $W^{B}$ does not depend on $D$. Second, we compute the value to the borrower at $(I, D)$ if $D \geq V^{L}(I)$. Finally, we fully characterize $W^{B}$.

Claim 1. If $D_{1}, D_{2} \geq V^{L}(I)$, then $W^{B}\left(I, D_{1}\right)=W^{B}\left(I, D_{2}\right)$.

This claim and proposition 1 imply that if there is debt overhang, the actual level of debt has no effect on the payoffs of the agents. Let $V^{B}(I)$ denote the value to the borrower at $(I, D)$ if $D \geq V^{L}(I)$. We refer to $V^{B}$ as the monopolistic value function of the borrower. Furthermore, we 
can assume that if $\left(R, K, D^{\prime}\right)$ is an equilibrium contract, then $D^{\prime} \leq$ $V^{L}(f(K)) .{ }^{13}$ We can also restrict our analysis to those $(I, D)$ states in which $D \leq V^{L}(I)$.

We have shown that if the monopolist could ignore the borrower's incentive constraint at $\left(0, V^{L}(0)\right)$, he would offer the contract $\left(0, K_{0}\right.$, $\left.V^{L}\left(f\left(K_{0}\right)\right)\right)$. Next, we show that this contract does satisfy the borrower's incentive constraint, and hence, this is the equilibrium contract.

Claim 2.

a. At state $(I, D), D \geq V^{L}(I)$, the borrower's payoff from rejecting all contracts is $I+\beta V^{B}(0)$.

$b$. The equilibrium contract at $\left(0, V^{L}(0)\right)$ is $\left(0, K_{0}, V^{L}\left(f\left(K_{0}\right)\right)\right)$.

Next, we characterize the monopolistic value function of the borrower. LEMMA 2.

$$
V^{B}(I)= \begin{cases}V^{B}(0) & \text { if } I<(1-\beta) V^{B}(0) \\ I+\beta V^{B}(0) & \text { otherwise. }\end{cases}
$$

In state $\left(0, V^{L}(0)\right)$ the investment $K_{0}$ is positive, and hence $V^{B}(0)>$ 0 . The borrower's outside option at $\left(I, V^{L}(I)\right)$ is $I+\beta V^{B}(0)$. Therefore, whenever $I+\beta V^{B}(0)<V^{B}(0)$, the monopolist can offer the same contract as the one at $\left(0, V^{L}(0)\right)$, except that $R=I$ instead of zero. The borrower strictly prefers accepting this contract to refusing it since it guarantees a payoff of $V^{B}(0)\left(>I+\beta V^{B}(0)\right)$. This shows that $V^{B}(I)=$ $V^{B}(0)$ whenever $I<(1-\beta) V^{B}(0)$. If $I+\beta V^{B}(0) \geq V^{B}(0)$, the monopolist lender makes the borrower indifferent between accepting the contract and rejecting it. Since the borrower's outside option is $I+\beta V^{B}(0)$, this implies $V^{B}(I)=I+\beta V^{B}(0)$.

The following proposition establishes the relationship between the functions $W^{B}, V^{B}$, and $V^{L}$.

Proposition 3. Suppose $D<V^{L}(I)$. Then $W^{B}(I, D)=V^{B}\left(I^{\prime}\right)$, where $I^{\prime}$ solves

$$
V^{L}\left(I^{\prime}\right)-I^{\prime}=D-I \text {. }
$$

Figure 1 represents the statement of proposition 3 graphically. The function $V^{L}$, depicted in figure $1 a$, defines the state space $\{(I, D), D \leq$ $\left.V^{L}(I)\right\}$. To find the value to the borrower at $(I, D)$, we draw a 45-degree line through the point $(I, D)$. This line intersects with the curve $V^{L}$ at $I^{\prime}$. Proposition 3 states that the value to the borrower at $(I, D)$ is $V^{B}\left(I^{\prime}\right)$, as shown in figure $1 b$.

Notice that $I^{\prime}$ defined by (8) depends only on $I-D$. Hence, an im-

${ }^{13}$ If $D^{\prime}=V^{L}(f(K))$, the incumbent has monopoly power in the next period for sure; hence, there is no point in specifying the next period's debt to be larger than $V^{L}(f(K))$. 


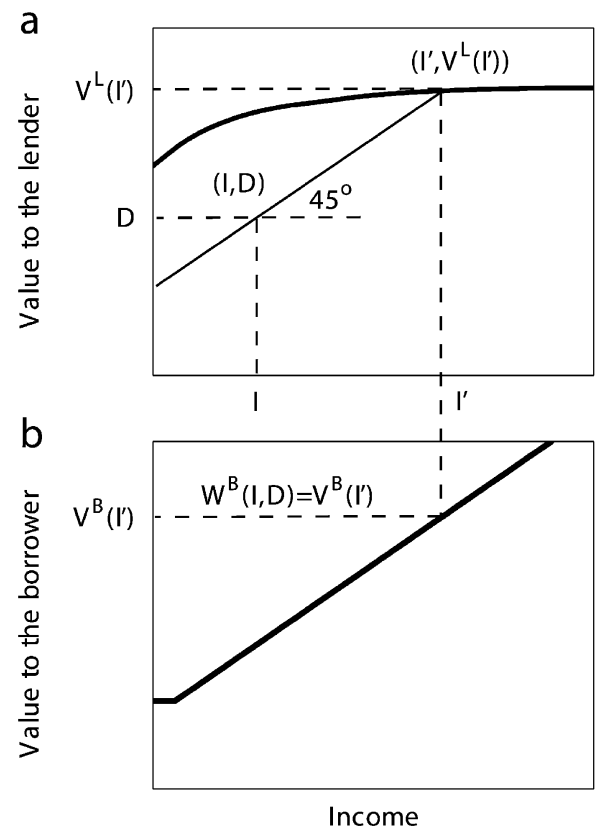

Fig. 1.-Illustration of proposition 3: $a$, value function of the lender, $V^{L} ; b$, value function of the borrower, $V^{B}$.

mediate consequence of the previous proposition is that the borrower's value, as long as the borrower does not face a debt overhang, depends only on her net position, that is, on the difference between her income and debt. (That is, the borrower's value is constant along the 45-degree line segment drawn in fig. 1a.) More precisely, if $D_{1}<V^{L}\left(I_{1}\right), D_{2}<$ $V^{L}\left(I_{2}\right)$, and $I_{1}-D_{1}=I_{2}-D_{2}$, then $W^{B}\left(I_{1}, D_{1}\right)=W^{B}\left(I_{2}, D_{2}\right)$. Let $H(I-D)$ denote the value to the borrower facing no debt overhang if her income is $I$ and her debt is $D$. By proposition 3,

$$
H(x)=V^{B}\left(Q^{-1}(x)\right)
$$

where $Q\left(I^{\prime}\right)=I^{\prime}-V^{L}\left(I^{\prime}\right)$.

\section{Marginal Values}

We turn our attention to characterizing the marginal values of income to the borrower and to the lender. Identifying these marginal values is crucial because they determine investment decisions and hence social welfare. We show that the marginal value of income to the borrower is greater than one if there is no debt overhang. We also prove that the 
marginal value of income to the monopolist incumbent is strictly smaller than one if the income of the borrower is sufficiently large.

Lemma 3. If $D<V^{L}(I)$, then

$$
H^{\prime}(I-D)=\frac{1}{1-V^{L \prime}\left(I^{\prime}\right)} \geq 1,
$$

where $I^{\prime}$ is defined by (8). Furthermore, $H$ is concave.

The term $H^{\prime}(I-D)$ is the marginal value to the borrower of an additional unit of income in state $(I, D)$. Recall from lemma 1 that $V^{L \prime} \in[0,1]$, which implies that $H^{\prime} \geq 1$. Since the borrower can consume the additional unit of consumption good, the marginal value is obviously at least one. The more interesting observation is that whenever $V^{L \prime}>$ 0 , the marginal value is strictly greater than one. The reason is that the borrower can use the additional income to reduce her debt. Reducing the debt gives the borrower access to a larger set of contracts, which allows her to make more efficient decisions. Hence, the borrower wants to reduce her debt as fast as possible. ${ }^{14}$ The goal of the rest of this section is to characterize the set of income realizations for which $V^{L \prime}<1$.

Suppose that the borrower has no debt and that her income is so high that it does not constrain her when she decides how much capital to buy. Then her maximization problem becomes

$$
\begin{aligned}
& \max _{R, K, D^{\prime}}-R+\beta E W^{B}\left(F(K), D^{\prime}\right) \\
& \text { subject to } R=E\left[K-\beta W^{L}\left(F(K), D^{\prime}\right)\right] .
\end{aligned}
$$

After plugging the constraint into the maximand, we can rewrite the problem as

$$
\max _{R, K, D^{\prime}} E\left[-K+\beta W^{L}\left(F(K), D^{\prime}\right)+\beta W^{B}\left(F(K), D^{\prime}\right)\right] .
$$

From lemma 3 and proposition 1 it follows that $\partial\left(W^{L}+W^{B}\right) / \partial D \leq 0$, and hence the borrower always (weakly) prefers a contract with $D^{\prime}=$ 0 and $R=K$. Therefore, the maximization problem can be rewritten as

$$
\max _{K}-K+\beta \int_{0}^{1} H(s f(K)) d G(s)
$$

\footnotetext{
${ }^{14}$ If the borrower could save, she would do so to avoid debt accumulation. Given our game, $D^{\prime} \geq 0$ since the lenders would default on any positive saving. Our results would hold even if we assumed that the lenders could not default on savings, as long as the savings were hit by random shocks.
} 
The first-order condition is

$$
-1+\beta f^{\prime}(K) \int_{0}^{1} H^{\prime}(s f(K)) s d G(s)=0 .
$$

Since $H$ is concave (see lemma 3 ), the second-order condition is automatically satisfied. Let $K_{M}$ denote the solution of the previous equality and

$$
I_{M}=\beta \int_{0}^{1} H\left(s f\left(K_{M}\right)\right) d G(s)-\beta V^{B}(0) .
$$

LEMMA 4.

$$
V^{L^{\prime}}(I) \begin{cases}=1 & \text { if } I \leq(1-\beta) V^{B}(0) \\ \in(0,1) & \text { if } I \in\left((1-\beta) V^{B}(0), I_{M}\right) \\ =0 & \text { if } I \geq I_{M},\end{cases}
$$

and $H^{\prime}(I-D)>1$ whenever $H(I-D)<I_{M}+\beta V^{B}(0)$. Furthermore, $H^{\prime}(0)>1$.

If $I \leq(1-\beta) V^{B}(0)$, the lender offers the same contract as the one at state $\left(0, V^{L}(0)\right)$, except that it specifies $R=I$. That is, the lender fully extracts the additional income from the borrower, showing $V^{L \prime}=1$ and $R=I$ in this domain. If $I \in\left((1-\beta) V^{B}(0), I_{M}\right)$, the lender still wants to extract an increase in the borrower's income via the immediate repayment, $R$. However, since $I+\beta V^{B}(0)>V^{B}(0)$, the increase in the repayment comes at a cost for the lender. In order to satisfy the incentive constraint of the borrower, the lender must compensate her by either increasing the capital investment or decreasing the debt in the next period. Hence, the lender's continuation value increases by less than one, showing that $0<V^{L \prime}<1$ and $R(I)=I$ on $\left((1-\beta) V^{B}(0), I_{M}\right)$. If $I \geq I_{M}$, the lender no longer wants to extract an increase in the borrower's income. The reason is that the capital investment at $\left(I_{M}\right.$, $\left.V^{L}\left(I_{M}\right)\right)$ is so high that its marginal product is very small. Furthermore, the next period's debt is already zero, so the lender cannot compensate the borrower by reducing $D^{\prime}$. Therefore, whenever $I \geq I_{M}$, the lender offers the same contract as the one at state $\left(I_{M}, V^{L}\left(I_{M}\right)\right)$, which shows that $V^{L \prime}=0$ and $R(I)=I_{M}$.

REMARK 1. Let $R(I)$ denote the repayment of the borrower at state $\left(I, V^{L}(I)\right)$. Then $R(I)$ is $I$ if $I<I_{M}$ and $I_{M}$ otherwise. 


\section{Main Results}

\section{A. Inefficient Investments}

Since each agent in our model is risk neutral, any welfare loss is due to inefficient investments. The next theorem identifies two sources of inefficiency.

Theorem 1. The monopolist lender invests too little if the borrower has low income. The borrower invests too much if she has small debt and high income. Formally, $K_{0}<K_{\mathrm{FB}}<K_{M}$.

Proof. First, we show that $K_{\mathrm{FB}}<K_{M}$. Notice that (10) implies

$$
\int_{0}^{1} H^{\prime}(s f(K)) s f^{\prime}(K) d G(s)>\int_{0}^{1} s f^{\prime}(K) d G(s) .
$$

The inequality is strict because $H^{\prime}(0)>1$, by lemma 4 . Therefore,

$$
\begin{aligned}
0 & =-1+\beta \int_{0}^{1} H^{\prime}\left(s f\left(K_{M}\right)\right) s f^{\prime}\left(K_{M}\right) d G(s) \\
& >-1+\beta \int_{0}^{1} s f^{\prime}\left(K_{M}\right) d G(s) .
\end{aligned}
$$

The previous inequality together with (1) implies $K_{M}>K_{\mathrm{FB}}$.

Second, we show that $K_{0}<K_{\mathrm{FB}}$. From lemma 4,

$$
\int_{0}^{1} V^{L \prime}(s f(K)) s f^{\prime}(K) d G(s)<\int_{0}^{1} s f^{\prime}(K) d G(s) .
$$

The inequality is strict because $f\left(K_{0}\right)>(1-\beta) V^{B}(0)$ (for otherwise the borrower would never consume). Therefore,

$$
\begin{aligned}
0 & =-1+\beta \int_{0}^{1} V^{L \prime}\left(s f\left(K_{0}\right)\right) s f^{\prime}\left(K_{0}\right) d G(s) \\
& <-1+\beta \int_{0}^{1} s f^{\prime}\left(K_{0}\right) d G(s)
\end{aligned}
$$

which together with (1) implies $K_{0}<K_{\mathrm{FB}}$. QED

If $I=0$, the borrower cannot compensate the monopolist lender by up-front payments for his investments. The lender's investment decision is driven by his ability to extract the next period's income. Since the borrower controls the income, the lender can extract it only at a cost. Hence, the marginal value of income to the monopolist is less than one, and thus he invests too little. On the other hand, if $I-D>K_{M}$, the borrower overinvests because by overinvesting she can reduce the prob- 
ability of debt overhang. The borrower wants to do so because she anticipates that if there is debt overhang, the incumbent lender will invest inefficiently little.

Investments $K_{0}$ and $K_{M}$ are made on large sets of states. Investment $K_{0}$ is made if $I \in\left[0,(1-\beta) V^{B}(0)\right]$ and $D \geq V^{L}(I)$. Investment $K_{M}$ is made whenever $I-D \in\left[K_{M}, \infty\right)$. We conjecture, but can show only by numerical computations, that in general the investment is positively correlated with income (see Secs. VI and VII).

Atkeson (1991) also shows that investment is inefficiently small for the lowest realizations of output. However, in his model, a moral hazard problem generates this result. The lender does not observe whether the borrower invests or consumes the borrowed funds. The investment is small if the realized income is small because this provides proper ex ante incentives for the borrower.

\section{B. Welfare Analysis}

Recall that if $D \leq V^{L}(I)$, the value to the borrower is $H(I-D)$ and the value to the lender is exactly $D$. Thus the social surplus at state $(I, D)$ is $H(I-D)+D$.

THEOREM 2.

a. Suppose that $V^{L}(I) \geq D_{1}>D_{2}$. Then

$$
H\left(I-D_{1}\right)+D_{1} \leq H\left(I-D_{2}\right)+D_{2} .
$$

Furthermore, the inequality is strict whenever $H\left(I-D_{2}\right)<I_{M}+$ $\beta V^{B}(0)$.

b. Suppose that $I_{1}>I_{2}$ and $V^{L}\left(I_{2}\right) \geq D$. Then

$$
H\left(I_{1}-D\right)+D \geq H\left(I_{2}-D\right)+D+\left(I_{1}-I_{2}\right) .
$$

Furthermore, the inequality is strict whenever $H\left(I_{2}-D\right)<I_{M}+$ $\beta V^{B}(0)$.

Proof. It follows from (10) and lemma 4 that $\partial H(I-D) / \partial I=$ $-\partial H(I-D) / \partial D \geq 1$, with strict inequality whenever $H(I-D)<I_{M}+$ $\beta V^{B}(0)$. Therefore, $\partial[H(I-D)+D] / \partial D=1-H^{\prime}(I-D) \leq 0$, with strict inequality whenever $H(I-D)<I_{M}+\beta V^{B}(0)$. This proves part $a$. Furthermore, $\partial[H(I-D)+D] / \partial I=H^{\prime}(I-D) \geq 1$, with strict inequality whenever $H(I-D)<I_{M}+\beta V^{B}(0)$, showing part $b$. QED

In a first-best world, the debt does not affect social surplus, and the investment is always $K_{\mathrm{FB}}$. According to part $a$, an increase in debt decreases social welfare because a larger debt implies less efficient investment decisions. The second part of the theorem says that an increase in the borrower's income $I$ increases the social surplus by more than the increase in I. The intuition is the same as before: The borrower's 
value increases by more than the increase in her income because she can use the additional income to repay debt and avoid debt overhang.

\section{Fluctuating Market Structures}

Theorem 3.

a. If the borrower faces a debt overhang, then there is a future date at which she regains access to the credit market. Formally, suppose that $D_{t} \geq V^{L}\left(I_{t}\right)$ at time $t$. Then, with probability one, there is a future date, $\tau$, at which $D_{\tau}<V^{L}\left(I_{\tau}\right)$.

$b$. If the borrower has access to the credit market, then there is a future date at which she faces a debt overhang. Formally, suppose that $D_{t}<V^{L}\left(I_{t}\right)$ at time $t$. Then, with probability one, there is a future date, $\tau$, at which $D_{\tau} \geq V^{L}\left(I_{\tau}\right)$.

When the borrower faces debt overhang, the incumbent lender acts as a monopolist. Clearly, the incumbent lender could offer a sequence of contracts that would guarantee him monopoly power forever no matter what shocks were realized. ${ }^{15}$ The first part of the theorem says that the incumbent does not find such a sequence of contracts to be optimal; after a while, he offers a contract that gives the borrower access to the competitive market next period with positive probability. The incumbent lender sometimes specifies the next period's debt such that, at least in high-income states, the borrower will not face debt overhang.

The argument for this result is as follows. Suppose that the lender never allowed the borrower to return to the competitive market. Then, at least in some states, the borrower's consumption would be positive, that is, $R<I$. Otherwise, the borrower would default whenever $I>0$. On the other hand, the borrower's gain from a marginal debt reduction exceeds the lender's loss (see proposition 1 and lemma 3). Since $R<$ $I$, the borrower can compensate the lender for a debt reduction. Hence, the monopolist incumbent would be better off increasing $R$ and decreasing the next period's debt, $D^{\prime}$. Hence, $R<I$ cannot be specified in the optimal contract, a contradiction.

Another way to understand why the monopolist incumbent lets the borrower have access to competitive markets is as follows. The most efficient way to extract surplus from the borrower is to guarantee efficient investment decisions to her. If the lender could commit to multiperiod contracts, he would promise to invest efficiently and not to extract income in the future in exchange for large immediate repay-

\footnotetext{
${ }^{15}$ The reason is that the monopolist lender can always offer a contract $(R, K$, $\left.V^{L}(f(K))\right)$ that the borrower prefers to default, i.e., a contract such that $I-R+$ $\beta E V^{B}(F(K)) \geq I+\beta V^{B}(0)$. An example of such a contract is $\left(\min \left\{I,(1-\beta) V^{B}(0)\right\}, K_{0}\right.$, $\left.V^{L}\left(f\left(K_{0}\right)\right)\right)$.
} 
ments. Such promises are not credible because of the lack of commitment. However, by lowering the next period's debt, the incumbent provides the borrower with access to the competitive market with positive probability. In the competitive market, the borrower can make more efficient investment decisions. Lowering the next period's debt serves as a commitment device for the incumbent. It can be viewed as a credible promise of the incumbent to invest more efficiently in the future.

Part $b$ says that debt overhang occurs with probability one. The borrower is hit by a sequence of bad shocks with probability one, along which she accumulates arbitrarily large debts. From the proof of the theorem, the following remark follows.

REMARK 2. If the borrower accumulates debt overhang, she regains access to the competitive credit market only after the realization of a sequence of good shocks.

\section{Buyback Boondoggle}

As we mentioned in the Introduction, several papers argue that borrowers do not benefit from organized buybacks. For example, Bulow and Rogoff (1988) report the following episode. In March 1988, Bolivia's foreign debt was selling at 6 cents on the dollar. Benefactors donated several million dollars to the Bolivian government for purposes of repurchasing part of the debt at these secondary market prices, which would allow the government to retire nearly half of the nominal value of the debt. However, after the repurchase, the market price on the debt rose to 11 cents. As a result, the market value of the total debt did not change. The burden of the Bolivians' external debt was no lower, and the buyback was just a transfer to the creditors. Bulow and Rogoff call this phenomenon a buyback boondoggle.

There are two ways to explain this phenomenon in our model, depending on whether the transfer from a third party is targeted at reducing debt directly or at increasing the borrower's income. Suppose that there is a debt overhang, $D>V^{L}(I)$. First, assume that a third party unexpectedly reduces the debt by an amount less than $D-V^{L}(I)$. Since the new debt still exceeds $V^{L}(I)$, the debt reduction is just a transfer to the incumbents but has no impact on the borrower's welfare. Second, suppose that $I<(1-\beta) V^{B}(0)$, and the donation increases the borrower's income by less than $(1-\beta) V^{B}(0)-I$. Since the borrower's payoff is constant on $\left[0,(1-\beta) V^{B}(0)\right]$ (see lemma 2 ), the borrower does not benefit from the transfer. The monopolist lender extracts the transfer from the borrower via an increase in $R$.

A shortcoming both of the analysis above and of Bulow and Rogoff (1988) is that they consider only what happens after debt overhang accumulates. Although the borrower might not benefit from buybacks 
ex post, third-party transfers still have an impact ex ante. The contracts offered in the credit market will reflect the lenders' anticipation of such transfers. Since the credit market is competitive, the borrower extracts all the surplus from buybacks ex ante.

\section{Numerical Computations}

We compute a numerical example and identify correlation coefficients of different variables. We provide the intuition behind these results and compare them with empirical facts on emerging market economies in the next section. Our purpose is to investigate whether the predictions of our model are qualitatively consistent with data, not to perform a serious calibration.

We present the computational results for the example in which $G$ is uniform, the production function $f(K)=2 K^{75}$, and the interest rate $r=(1 / \beta)-1=0.1$. To find the fixed point of the operator $T$ defined in Appendix B, we use the value function iterations approach. We obtained convergence to the same limit every time the program was run, with different initial guesses. Next we describe the value and policy functions. Then we analyze the generated time series.

\section{A. $\quad$ Solution to the Monopolist's Problem}

Below, we describe computed monopolistic value functions, $V^{B}(I)$ and $V^{L}(I)$, and the corresponding policy functions of investment and the next period's debt, $K(I)$ and $D^{\prime}(I)$. From proposition 3, the competitive contract at state $(I, D)$ is $\left(R\left(I^{\prime}\right)-I^{\prime}+I, K\left(I^{\prime}\right), D^{\prime}\left(I^{\prime}\right)\right)$, where $\left(R\left(I^{\prime}\right)\right.$, $\left.K\left(I^{\prime}\right), D^{\prime}\left(I^{\prime}\right)\right)$ is the equilibrium contract at $\left(I^{\prime}, V^{L}\left(I^{\prime}\right)\right)$, and $I^{\prime}$ solves equation (8). This gives us the competitive policy functions. The competitive value functions are $W^{B}(I, D)=V^{B}\left(I^{\prime}\right)$ and $W^{L}(I, D)=D$.

\section{Monopolistic Value Functions}

Figure 2 plots the monopolistic value functions, $V^{B}(I)$ and $V^{L}(I)$. As lemma 2 claims, $V^{B}(I)$ is $V^{B}(0)$ on $\left[0,(1-\beta) V^{B}(0)\right]$ and $I+\beta V^{B}(0)$ otherwise. The shape of the lender's value function, $V^{L}$, is as described in lemmas 1 and 4 . In particular, $V^{L}(I)$ is increasing and concave. It has slope one on $\left[0,(1-\beta) V^{B}(0)\right]$, then gradually becomes flat, and the slope becomes zero at $I=I_{M}$.

\section{Monopolistic Policy Functions}

Recall that the more income the borrower has, the more difficult it is for the lender to fully extract the income. The lender has two instru- 
a

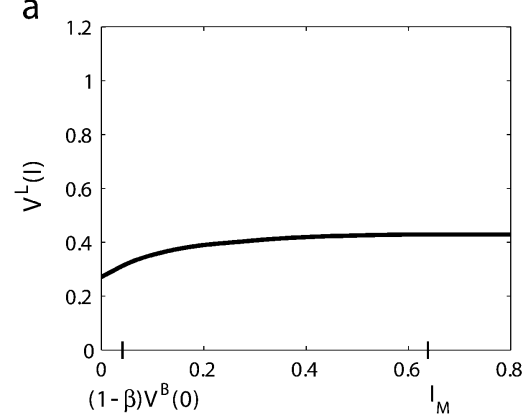

b

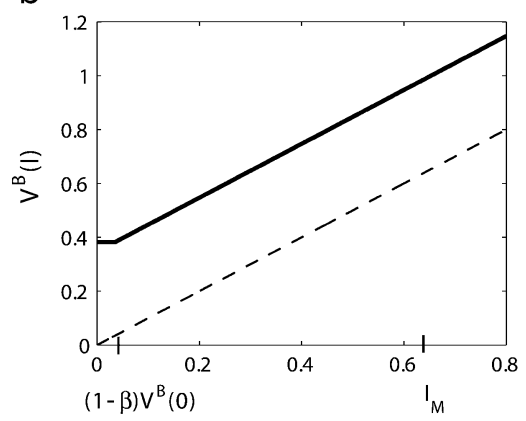

Fig. 2.-Monopolistic value functions: $a$, value function of the lender, $V^{L}(I) ; b$, value function of the borrower, $V^{B}(I)$.

a

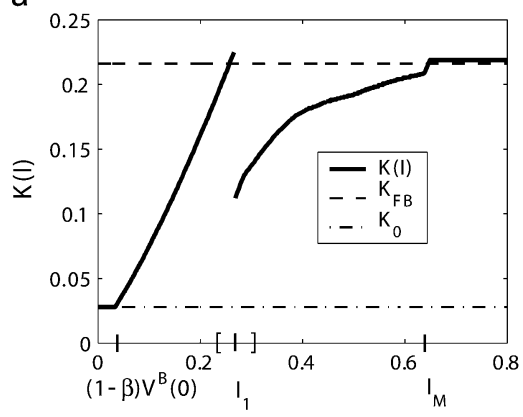

b

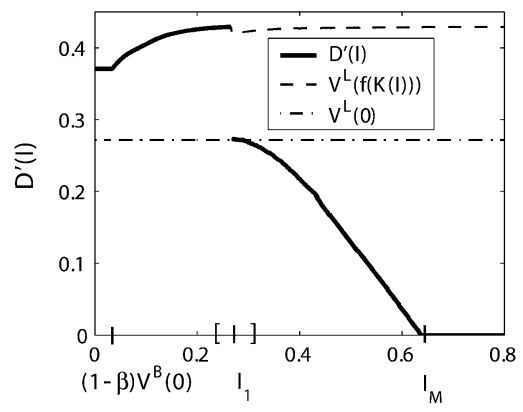

Fig. 3.-Monopolistic policy functions: $a$, investment, $K(I)$; $b$, next period's debt, $D^{\prime}(I)$.

ments to extract an increase in income through current repayment: $\mathrm{He}$ either increases the investment or decreases the next period's debt. In what follows, we analyze how the lender uses these instruments as a function of the borrower's income.

Figure 3 shows the monopolist's choice of investment and the next period's debt as functions of income. These functions are defined as if only deterministic contracts were allowed, but the value functions are generated by potentially random contracts. At the end of this subsection, we explain how the lender randomizes among these contracts.

Notice that if the next period's debt is $V^{L}(f(K(I)))$ or higher, the lender will have monopoly power in the next period for sure. Whenever $D^{\prime}(I)<V^{L}(f(K(I)))$, the borrower will have access to competitive markets in the next period with positive probability. Debt reduction occurs if the realization of $V^{L}(F(K(I)))$ exceeds $D^{\prime}(I)$. If the next period's debt 
lies below $V^{L}(0)$, the borrower surely avoids debt overhang in the next period.

The interval $\left[0,(1-\beta) V^{B}(0)\right]$.-As we have shown in claim 2, when $I=0$, the lender invests a positive amount of capital, $K_{0}$. The investment is smaller than the socially efficient level (see theorem 1 ). Notice that $K_{0}$ is the smallest investment the lender ever makes. Since the borrower cannot compensate the lender for a debt reduction, the next period's debt, $D^{\prime}$, is set to $V^{L}\left(f\left(K_{0}\right)\right)$. This means that the lender surely remains a monopolist next period. If $I \in\left[0,(1-\beta) V^{B}(0)\right]$, the same decisions are made about $K$ and $D^{\prime}$.

The interval $\left[(1-\beta) V^{B}(0), I_{1}\right]$. - It turns out that allowing the borrower to regain access to the competitive market with only a small probability is not profitable to the lender; providing more investment is a better way to increase the borrower's continuation value. Hence, if a debt reduction ever occurs, it has to correspond to a discontinuity of the curve $D^{\prime}(I)$. Let $I_{1}$ denote the level of income at which this discontinuity occurs. On the interval $\left[(1-\beta) V^{B}(0), I_{1}\right]$, the lender uses only investment to extract the borrower's income, and $D^{\prime}(I)$ is so high that the lender surely keeps his monopoly power.

The interval $\left[I_{1}, \infty\right)$.-At $I_{1}$ the lender discontinuously reduces the next period's debt of the borrower. Since there is a discontinuous drop in $D^{\prime}$, there is also a discontinuous drop in investment in order to keep $V^{B}$ continuous. It can be seen from the figure that $D^{\prime}$ is reduced to $V^{L}(0)$; that is, the borrower returns to competition for sure in the next period. We do not have an analytical result that would support this observation. On $\left[I_{1}, \infty\right), K(I)$ is increasing and $D^{\prime}(I)$ is decreasing. Eventually the next period's debt reaches zero. Investment continues to rise shortly after that, until $I_{M}$, where investment settles at $K_{M}\left(>K_{\mathrm{FB}}\right)$. No additional surplus can be extracted from that point on, so the policy functions are constant to the right of $I_{M}$.

Randomization.-The discrete jump in the policy functions at $I_{1}$ translates into nonconcavity of the lender's value function. Therefore, around $I_{1}$ the monopolist will use random contracts to increase his value. In figure 3 this interval of nonconcavity is marked with brackets on the horizontal axis. Let $[I, I]$ denote this interval. At income level $I \in(I$, $\dot{I})$, the lender offers a random contract that mixes $\left(R(I), K(\underline{I}), D^{\prime}(\underline{I})\right)$ with probability $\pi$ and $\left(R(I), K(\bar{I}), D^{\prime}(\bar{I})\right)$ with probability $1-\pi$, where $\pi=(I-\underline{I}) /(\bar{I}-\underline{I})$. The lender uses only deterministic contracts everywhere else.

Along the equilibrium path, the maximum possible level of income realization under monopoly is smaller than $I_{M}$. That is, the monopolist always underinvests and never forgives the debt in full, and $R(I)=I$ always. 

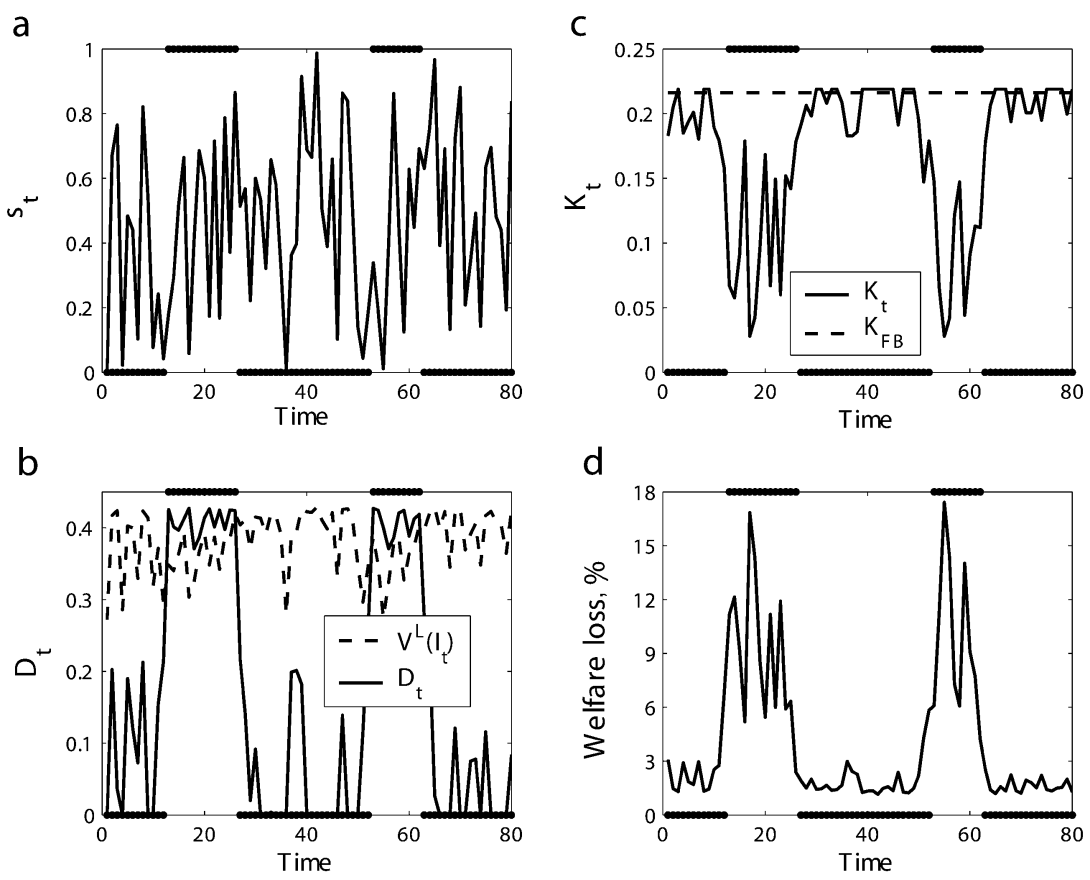

FIG. 4.-Time series: $a$, shocks, $s_{i} ; b$, debt, $D_{i} ; c$, investment, $K_{i}$; $d$, welfare loss

\section{B. Time Series}

Starting from state $(0,0)$ and generating a random sequence of productivity shocks, we calculate the resulting paths of the main variables for 300,000 periods. The graphs here show the first 80 periods of this simulation. Figure 4 plots the time series of productivity shocks, investment, debt, and welfare loss. The black dots appear at the top of each panel when there is monopoly and at the bottom when there is competition.

Market structure.-Figure 4 shows how the structure of the credit market fluctuates between the two regimes, as theorem 3 predicts. Notice that debt overhang occurs after a sequence of bad shocks, and competition is restored after good shocks. The proportion of periods of monopoly power is 10.9 percent, and the average length of the monopolistic regime is 3.9 periods. A switch in regime (from monopoly to competition and vice versa) occurs in 5.6 percent of the periods.

Debt.-The solid line in figure $4 a$ shows the time path of the borrower's debt, $D_{t}$. The dashed line depicts $V^{L}\left(I_{t}\right)$. The debt level is below $V^{L}\left(I_{t}\right)$ when the asset market is competitive. If there is monopoly, $D_{t} \geq V^{L}\left(I_{t}\right)$, 
the solid line is above the dashed line. Notice that even after the borrower returns to competition, she continues to reduce her debt.

Investment.-On average, monopoly involves lower investment than competition. The average investment during competition is 94.6 percent of the first-best investment, $K_{\mathrm{FB}}$, and the average investment during monopoly is 51.2 percent of $K_{\mathrm{FB}}$.

Welfare.-Figure $4 d$ plots the time series of the welfare loss in percentage terms, computed as

$$
\frac{S_{\mathrm{FB}}\left(I_{t}\right)-\left[W^{B}\left(I_{t}, D_{t}\right)+W^{L}\left(I_{t}, D_{t}\right)\right]}{S_{\mathrm{FB}}\left(I_{t}\right)} \cdot 100 .
$$

The average welfare loss is 2.7 percent. However, conditional on the monopoly regime, this loss is 8.6 percent; conditional on competition, the loss is only 2 percent. The investment graph shows that the welfare loss is almost solely due to underinvestment, not to overinvestment.

\section{Empirical Evidence}

\section{A. Correlations}

Table 2 reports correlation coefficients between certain variables for the time-series simulations. We compare these results with stylized facts described in the literature.

The first row of table 2 shows the correlation coefficient between the indicator of the market structure and other variables. The correlation between the monopoly indicator and investment is -0.72 . The reason is that monopoly is associated with lower investment on average compared with competition. This is consistent with empirical observations. We interpret the time interval between default and debt reduction as the periods of monopoly power in our model. Deshpande (1997) documents that the 1980s debt crises were associated with a drastic fall in investment. In particular, for the highly indebted countries (HICs), in-

TABLE 2

Correlation Coefficients

\begin{tabular}{lrrrrr}
\hline \hline & $I_{t}$ & $D_{t}$ & $K_{t}$ & $D_{t+1}$ & $C_{t}$ \\
\hline Market structure indicator, & & & & & \\
$\quad=1 / 0$ if monopoly/competition & -.21 & .80 & -.72 & .66 & -.25 \\
Investment, $K_{t}$ & .58 & -.71 & & & \\
Next period's debt, $D_{t+1}$ & -.67 & .75 & -.82 & & \\
$\begin{array}{l}\text { Probability of debt overhang next } \\
\text { period }\end{array}$ & -.38 & .67 & -.72 & .80 & \\
$\quad \begin{array}{l}\quad \\
\quad r_{t}=\left[D_{t+1} /\left(D_{t}+K_{t}-R_{t}\right)\right]-1\end{array}$ & -.39 & .68 & -.77 & .79 & -.25 \\
Net borrowing, $K_{t}-R_{t}$ & -.58 & -.46 & & & \\
\hline
\end{tabular}


vestment declined at an average annual rate of 5.3 percent from 1980 to 1987 . Per capita investment fell by about 40 percent. Fischer (1987) reports that investment fell by 5-7 percent of GNP between 1981 and 1985 for some indebted countries. According to Borensztein (1990a), the average investment to GDP ratio for 15 HICs was 18 percent in 1982-87, compared with a 24 percent average ratio in 1971-81. Furthermore, Arslanalp and Henry (2005) show that the countries that received debt relief under the Brady deal between 1989 and 1995 experienced an investment boom soon after the deals were made. The average growth rate of capital in these countries increased from 1.6 percent per year five years before the debt relief to 3.5 percent per year during the five years after the debt relief. This evidence is consistent with our result that investment rises after a debt buyback.

The correlation coefficient between investment, $K_{t}$, and the amount of debt, $D_{t}$, is -0.71 . This can partly be explained by the association of periods of monopoly power with higher debt levels. (The correlation coefficient between the indicator function for a monopoly period and current debt is 0.80.) Also, as we have shown, investment is small during the monopoly regime. However, even during the competitive regime, investment is smaller when debt is larger, because the borrower uses her money to repay debt instead of buying capital. Empirical studies have confirmed this negative effect of debt on investment. For example, Arrau (1990) finds this effect for the 1980s debt crisis in Mexico. Borensztein (1990b) estimates a positive impact of debt reduction on investment in the Philippines. Deshpande (1997) finds a negative relationship between debt and investment for 13 HICs between 1971 and 1991. Fry (1989) confirms this finding for 28 developing countries that were highly indebted to the World Bank in 1986. Greene and Villanueva (1991) show that the rate of private investment is negatively related to the debt-service ratio and the ratio of debt to GDP in a sample of 23 developing countries over the period 1975-87.

Owing to low investment, income is also low under the monopoly regime. The correlation coefficient between the borrower's income and the monopoly indicator is -0.21 . Arslanalp and Henry (2005) report that after debt relief, the Brady countries experienced a sharp rise in per capita GDP growth rates, in line with this prediction. In addition, our result is consistent with the observation that sovereign debt crises result in output losses. Sturzenegger (2004) provides evidence from growth regressions for a large sample of developing countries and finds that countries that defaulted in the 1980s experienced lower GDP growth than those that did not default. The author estimates an accumulated 4 percent drop in output over the immediately following four years.

There is a positive relationship between investment, $K_{t}$, and the in- 
come of the borrower, $I_{i}$; the corresponding correlation coefficient is 0.58 . When the borrower has more income, she can afford more investment. Similarly, when income is higher, the borrower is more likely to be able to afford the next period's debt reduction if there is monopoly and to repay debt if there is competition. The correlation coefficient between $I_{t}$ and $D_{t+1}$ is negative: -0.67 .

Many authors have argued that a large amount of debt increases the probability of default and hence must be associated with higher risk premia. Recent papers that discuss this issue include Arellano (2005) and Yue (2005). Providing empirical support for this argument, Edwards (1984) estimates a positive effect of the debt-output ratio on the country interest rate spread over the London interbank offered rate for 19 countries between 1976 and 1980. Edwards (1986) confirms this finding using data on Eurocurrency loans granted to 26 developing countries and on bonds issued by 13 developing countries during the same time period. Our model also generates a negative relationship between debt and country risk. Higher debt today makes debt overhang tomorrow more likely. (The correlation between $D_{t}$ and the probability of debt overhang next period is 0.67.) This in turn raises the risk premium on the country's loans. ${ }^{16}$ (The correlation between $D_{t}$ and the country interest rate is 0.68.) In addition, Edwards (1984) finds that country bond spreads are negatively related to gross domestic investment over GDP. The author's explanation is that higher investment indicates that the country has good prospects for future growth, which should decrease the probability of default and hence the risk premium. Consistent with this finding, we find a strong negative correlation between investment and the country interest rate: -0.77 .

A number of studies document that default risk and default premia are highly countercyclical in emerging economies. Neumeyer and Perri (2005) report countercyclicality of real interest rates for Argentina (1983-2001) and Brazil, Mexico, Korea, and the Philippines (19942001). Uribe and Yue (2006) also document a negative relationship between country spreads and output for Argentina, Brazil, Ecuador, Mexico, Peru, the Philippines, and South Africa over the period 19942001. Estimating a vector autoregression model, they find that country spread shocks explain 12 percent of movements in output, and output explains 12 percent of the movements of country interest rates. ${ }^{17} \mathrm{Ed}-$ wards (1984), Cline (1995), and Cline and Barnes (1997) find that GDP

\footnotetext{
${ }^{16}$ At state $\left(I_{t}, D_{t}\right), D_{t} \leq V^{L}\left(I_{t}\right)$, the country interest rate is defined as $r_{t}=\left[D_{t+1} /\left(D_{t}+\right.\right.$ $\left.\left.K_{t}-R_{t}\right)\right]-1$. The world risk-free interest rate is $r=(1 / \beta)-1$. It is easy to show that $r_{t}>r$ if $D_{t+1}>V^{L}(0)$ (i.e., if the probability of debt overhang next period is strictly positive), and $r_{t}=r$ otherwise.

${ }^{17}$ Arellano (2005), Yue (2005), and Aguiar and Gopinath (2006) build models that match the countercyclicality of country interest rates in the Argentine economy.
} 
growth is a significant determinant of country spreads in developing countries. In our simulations, we obtain a correlation coefficient of -0.39 between the borrower's income and the country interest rate, and a correlation coefficient of -0.38 between income and the probability of debt overhang next period.

Our model also generates a negative correlation between consumption, $C_{t}=I_{t}-R_{t}$, and the country interest rate $(-0.25)$, consistent with empirical observations. For example, Arellano (2005) reports it for Argentina for the last decade. She also documents that the dynamics of interest rates, consumption, output, and current account around the 1999 default episodes in Russia and Ecuador are similar to those in Argentina.

Arellano (2005), Yue (2005), and Aguiar and Gopinath (2006, 2007) suggest that an empirical regularity of emerging market economies, in particular Argentina, is a countercyclical current account. In other words, countries tend to borrow more (and at lower interest rates) in booms than in recessions. The models of Aguiar and Gopinath (2006) and Yue (2005) introduce persistent shocks. Hence, when the borrower receives a good endowment shock, her permanent income rises by more than her current income, which induces her to borrow in order to smooth consumption. In our model, good shocks are associated with higher investment. However, net borrowing, $K_{t}-R_{t}$, is negatively correlated with output. (The correlation coefficient is -0.58 .) The reason is that the borrower always wants to repay her debt, and in good states the borrower can afford to repay more. However, the shocks in our setup are independently and identically distributed. Introducing persistence in the shock process would have two effects. First, a high shock today would predict a high shock tomorrow, which would make investment in the current period more productive. This would induce higher investment and higher borrowing. Second, higher income today would translate into higher future expected income, which would decrease the threat of debt overhang. The borrower could then choose to delay part of the debt repayment and use her income to buy more capital. This again would increase net borrowing. Our conjecture is that persistence in productivity shocks can result in more borrowing in good states, but for reasons other than consumption smoothing, in contrast to the existing literature.

\section{B. Debt Reductions after a Sequence of Good Shocks}

One of the predictions of our model is that debt reductions occur after a sequence of good shocks (see remark 2). In this subsection, we show that empirical evidence supports this prediction. 
1. The Brady Plan

One major example of debt relief is the Brady plan announced in 1989 in response to the 1980s sovereign debt crisis. This plan resulted in debt reduction deals for 18 countries during the following decade. The 1980s debt crisis was caused mainly by worldwide events in the 1970s and 1980s, including oil price shocks, high interest rates, recession in industrial countries, and low commodity prices. The HICs accumulated debt overhang, and the crisis became apparent when in 1982 Mexico announced that it could not honor its debt obligations. From 1982 to 1988, debtor countries and commercial bank creditors engaged in repeated rounds of debt rescheduling that proved useless in solving the sovereign debt crisis.

In 1989, U.S. Treasury Secretary Nicholas Brady announced a plan that encouraged the creditors to engage in voluntary debt reduction schemes. Existing loans were swapped for either discount bonds (lesser face value but with a market-based floating rate of interest) or par bonds (equal face value but with a fixed, below-market interest rate). Both types of bonds had a 30-year maturity. In some cases, commercial banks and multilateral agencies provided new loans. Brady bonds were issued by Argentina, Bolivia, Brazil, Bulgaria, Costa Rica, the Dominican Republic, Ecuador, Ivory Coast (Côte d'Ivoire), Jordan, Mexico, Nigeria, Panama, Peru, the Philippines, Poland, Uruguay, Venezuela, and Vietnam. The total face value of the Brady bonds was more than $\$ 150$ billion. A typical deal resulted in forgiving 30-35 percent of a country's debt. ${ }^{18}$

In accordance with our model, we view the time in which the countries were unable to service their debt as the period of debt overhang and monopoly power. To see whether our prediction that a debt reduction occurs after a sequence of good shocks holds in this case, we look at the real GDP growth rates of the 18 countries that issued Brady bonds. Different countries received debt reductions in different years, between 1990 and 1998. We average the growth rates of these countries such that the last year in each country's time series is the year in which the Brady deal was made for that country. We plot the obtained average growth rate in figure $5 a$. Notice how growth is higher a few years before the Brady deal, just as the model predicts. The average growth rate of the Brady countries three years before the debt relief deal was 4.1 percent, compared with 1.8 percent during the six years preceding those three years, a difference of 2.3 percent. Case by case, the experience in more than two-thirds of the countries is consistent with the model's prediction. In addition, for eight out of the 18 countries, the difference

${ }^{18}$ For a discussion, see, e.g., Arslanalp and Henry (2005) and Chuhan and Sturzenegger (2005). 
a

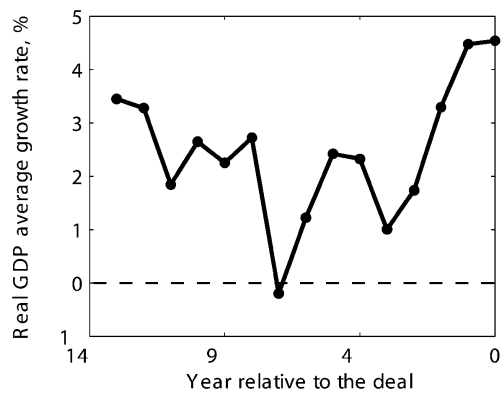

b

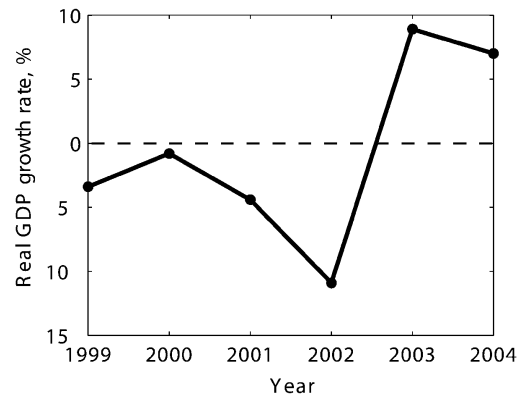

FIG. 5.-GDP growth prior to debt relief: $a$, Brady countries (data source: United Nations); $b$, Argentina (data source: International Monetary Fund).

in average growth rates between the last three years before the deal and the preceding six years exceeds 3.3 percent.

\section{2005 Argentine Debt Swap}

The most recent sovereign debt reduction, and the largest in history, is the 2005 Argentine debt swap deal. In December 2001, after four years of deepening recession, Argentina's government ceased all debt payments. After three years of default, Argentina made an offer that would involve a 70-75 percent reduction in the net present value of its debt, provided that at least 70 percent of the bondholders agreed with the arrangement. The $\$ 102.6$ billion debt swap closed on February 25, 2005 , and was the largest write-down in the history of sovereign restructurings.

Looking at Argentina's real GDP growth rate (fig. $5 b$ ), one can see that 2003 and 2004 are the years of good shocks, following our model's language. During these two years, real GDP in Argentina grew at 8 percent, compared with an average of -4.9 percent during the years 1999-2002, a difference of almost 13 percent. Again, just as our theory predicts, the debt relief follows a sequence of good shocks.

The Brady deal and the recent debt swap by Argentina empirically support our model's predictions that the borrower achieves a debt reduction after favorable shocks. This observation is in sharp contrast to the predictions of the rest of the literature on sovereign debt renegotiation. Most of the existing models assume that once the borrower decides not to serve debt in full, the parties engage in bilateral renegotiation. Since there is no delay in bargaining, the debt reduction agreement is achieved immediately. Hence these models predict that 
the debt reduction occurs when the borrower cannot repay the debt, that is, after a sequence of bad shocks.

\section{Discussion}

The main idea of this paper was based on the observation that accumulated debt is a sunk cost for the incumbent lenders but not for new potential lenders. This asymmetry gives ex post market power to the incumbents. Our goal was to explore the consequences of this phenomenon for financial contracting. Our main result is that the structure of the asset market keeps changing over time. In particular, even if the incumbents have monopoly power over the borrower, they find it optimal to let the borrower have access to the competitive credit market at a future date. This seems to be particularly relevant in explaining defaults and debt reductions in the context of sovereign lending.

Our model captures a fundamental conflict between the borrower and the lenders. On the one hand, the borrower needs the capital of the lenders; on the other hand, the borrower receives the realized income. The marginal value to the monopolist lender of the borrower's income is less than one, because it is costly for the lender to extract income from the borrower. Therefore, in general, the monopolist lender invests less than the socially efficient amount. Because of this inefficiency, the borrower wants to avoid debt overhang by repaying her debt as fast as possible. The borrower's marginal value of income is greater than one, because she can use extra income to lower her debt. By lowering debt, the borrower may avoid debt overhang and can make more efficient investment decisions than the lenders would.

The borrower's large marginal value of income, which is also her marginal value of debt reduction, explains our main result. If the borrower has enough liquidity, the monopolist lender can extract income from her by reducing debt. Since the lender's marginal value of debt is one, which is less than the marginal value to the borrower, the monopolist lender can extract more current repayment from the borrower than the lender's loss due to a debt reduction.

Two assumptions were essential in obtaining our results. First, the contracts in our model are incomplete. Although we assumed that debt cannot be contingent on the realized income at all, what we really need is that debt cannot be perfectly indexed by the shocks. This would already imply that debt can be accumulated, giving market power to the incumbents. Second, we assume that the incumbent lenders can 
coordinate their actions. Indeed, we model the incumbents as a single agent. We believe that neither of these assumptions is far-fetched. ${ }^{19}$

We have shown that our computational results are consistent with many empirical observations on emerging market economies. In addition, unlike other papers, our model predicts that debt reductions should happen only after a sequence of good shocks. We show this to be consistent with data.

\section{Appendix A}

\section{Omitted Proofs}

Proof of Proposition 1

First, we prove that $W^{L}(I, D) \leq \min \left\{D, V^{L}(I)\right\}$. The inequality $W^{L}(I, D) \leq V^{L}(I)$ follows from the definition of $V^{L}$. We have to show that $W^{L}(I, D) \leq D$. Suppose by contradiction that $W^{L}(I, D)>D$, and the contract accepted at $(I, D)$ is $(R, K$, $\left.D^{\prime}\right)$. Then the outsider could offer a contract $\left(R-\epsilon, K, D^{\prime}\right)$, where $\epsilon \in(0$, $\left.W^{L}(I, D)-D\right)$. This contract is feasible at $(I, D)$, and the borrower strictly prefers it to $\left(R, K, D^{\prime}\right)$ because $\epsilon>0$. The outsider's payoff from this contract is $W^{L}(I$, $D)-D-\epsilon$, which is strictly positive. This contradicts the hypothesis that the equilibrium contract was $\left(R, K, D^{\prime}\right)$.

It remains to show that $W^{L}(I, D) \geq \min \left\{D, V^{L}(I)\right\}$. Suppose that the incumbent offers the same contract at $(I, D)$ as the one accepted at $\left(I, D^{\prime}\right)$. If the borrower accepted this contract, the incumbent's payoff would be $W^{L}\left(I, D^{\prime}\right)$. If the outsider offers a more attractive contract to the borrower, the incumbent would receive $D{ }^{20}$ This proves that $W^{L}(I, D) \geq \min \left\{D, W^{L}\left(I, D^{\prime}\right)\right\}$ for all $D^{\prime}$. Since $V^{L}(I)=$ $\sup _{D} W^{L}(I, D), W^{L}(I, D) \geq \min \left\{D, V^{L}(I)\right\}$ follows. QED

Proof of Proposition 2

a. Suppose that $D<V^{L}(I)$. First, notice that

$$
D=W^{L}(I, D)=R^{*}+E\left[-K^{*}+\beta W^{L}\left(F\left(K^{*}\right), D^{*}\right)\right],
$$

where the first equality follows from proposition 1 and the second one from the definition of $W^{L}$. This shows that $\left(R^{*}, K^{*}, D^{*}\right)$ satisfies (3) with equality. It remains to show that $\left(R^{*}, K^{*}, D^{*}\right)$ maximizes (4) subject to (3). Suppose by contradiction that there is a feasible contract $\left(R_{2}, K_{2}, D_{2}^{\prime}\right)$ satisfying (3) and being strictly preferred by the borrower to $\left(R^{*}, K^{*}, D^{*}\right)$. Let $\left(R_{3}, K_{3}, D_{3}^{\prime}\right)$ denote the equilibrium contract at state $\left(I, D^{\prime \prime}\right)$, where $D<D^{\prime \prime}<V^{L}(I)$. By proposition 1 the continuation payoff of the outsider from this contract is $D^{\prime \prime}$. Consider the probability mixture of $\left(R_{2}, K_{2}, D_{2}^{\prime}\right)$ and $\left(R_{3}, K_{3}, D_{3}^{\prime}\right)$, where $\left(R_{3}, K_{3}, D_{3}^{\prime}\right)$ is offered with probability $\epsilon$. If $\epsilon$ is small, the borrower strictly prefers this mixture

\footnotetext{
${ }^{19}$ Assuming coordination among lenders is consistent with sovereign debt renegotiation made through the London Club or the Paris Club, as well as with the use of common action clauses in sovereign bond issues. The London and Paris Clubs organize coordination among lenders. The inclusion of common action clauses allows the terms of a contract to change only if a predetermined supermajority of bondholders consent. For a discussion of these issues, see Sturzenegger and Zettelmeyer (2005, chap. 1).

${ }^{20}$ It can be shown that it cannot happen that the borrower rejects all the contracts.
} 
to $\left(R^{*}, K^{*}, D^{*}\right)$. In addition, the outsider's payoff from this mixture is $\epsilon D^{\prime \prime}+$ $(1-\epsilon) D>D$. Hence, $\left(R^{*}, K^{*}, D^{*}\right)$ cannot be the equilibrium contract because the outsider could offer the mixture and become the incumbent.

$b$. The contract $\left(R^{*}, K^{*}, D^{*}\right)$ must satisfy (2). Suppose by contradiction that $\left(R^{*}, K^{*}, D^{*}\right)$ does not maximize (5) subject to (2). Then there exists a contract $\left(R_{2}, K_{2}, D_{2}^{\prime}\right)$ satisfying (2) and

$$
R_{2}+E\left[-K_{2}+\beta W^{L}\left(F\left(K_{2}\right), D_{2}^{\prime}\right)\right]>R^{*}+E\left[-K^{*}+\beta W^{L}\left(F\left(K^{*}\right), D^{*}\right)\right] .
$$

Consider a contract $\left(R_{2}-\epsilon, K_{2}, D_{2}^{\prime}\right)$, where $\epsilon>0$. Since $\left(R_{2}, K_{2}, D_{2}^{\prime}\right)$ satisfies (2), the borrower strictly prefers accepting $\left(R_{2}-\epsilon, K_{2}, D_{2}^{\prime}\right)$ to rejecting it. If $\epsilon$ is small, this contract generates a strictly higher payoff to the lender than $\left(R^{*}, K^{*}, D^{*}\right)$. This shows that $\left(R^{*}, K^{*}, D^{*}\right)$ cannot be an equilibrium contract. QED

\section{Proof of Lemma 1}

a. Suppose that $I^{\prime}>I, D>\max \left\{V^{L}\left(I^{\prime}\right), V^{L}(I)\right\}$, and the contract accepted at $I$ is $\left(R, K, D^{\prime}\right)$. Then the contract $\left(R-\epsilon, K, D^{\prime}\right)$, where $\epsilon>0$, satisfies (2) with strict inequality and is feasible at $I^{\prime}$. Hence, at $I^{\prime}$ the borrower strictly prefers accepting the contract $\left(R-\epsilon, K, D^{\prime}\right)$ to rejecting it. The lender's payoff from this contract would be $V^{L}(I)-\epsilon$, showing that $V^{L}\left(I^{\prime}\right) \geq V^{L}(I)-\epsilon$. Since this is true for all $\epsilon>0, V^{L}\left(I^{\prime}\right) \geq V^{L}(I)$ follows.

$b$. Suppose that $\delta>0, D>V^{L}(I+\delta)$, and the contract accepted at $I+\delta$ is $(R$, $\left.K, D^{\prime}\right)$. Then the contract $\left(R-\delta, K, D^{\prime}\right)$ is feasible at $I$. Notice that

$$
\begin{aligned}
I-(R-\delta)+\beta E W^{B}\left(F(K), D^{\prime}\right) & =I+\delta-R+\beta E W^{B}\left(F(K), D^{\prime}\right) \\
& \geq I+\delta+\beta W^{B}(0, D / \beta)>I+\beta W^{B}(0, D / \beta),
\end{aligned}
$$

where the weak inequality holds because $\left(R, K, D^{\prime}\right)$ satisfies (2) at $I+\delta$. This shows that at $I$ the borrower strictly prefers accepting $\left(R-\delta, K, D^{\prime}\right)$ to rejecting it. The lender's payoff from this contract is

$$
R-\delta+E\left[-K+\beta W^{L}\left(F(K), D^{\prime}\right)\right]=V^{L}(I+\delta)-\delta .
$$

This shows that $V^{L}(I) \geq V^{L}(I+\delta)-\delta$.

$c$. The concavity of $V^{L}$ follows from the assumption that random contracts are allowed. QED

Claim 3. Suppose that at $(I, D)$ such that $D \geq V^{L}(I), I-R+\beta E W^{B}(F(K)$, $\left.D^{\prime}\right)>I+\beta W^{B}(0, D / \beta), \quad R+E\left[-K+\beta W^{L}\left(F(K), D^{\prime}\right)\right] \geq V^{L}(I)$, and $R \leq I$. Then $(R, K)=\left(I, K_{0}\right)$ and $D^{\prime} \geq V^{L}\left(f\left(K_{0}\right)\right)$. In addition, the equilibrium contract at $(I, D)$ is $\left(I, K_{0}, D^{\prime}\right)$.

Proof. This claim says that if $\left(R, K, D^{\prime}\right)$ is feasible, provides the lender with a payoff of $V^{L}(I)$, and satisfies the borrower's incentive constraint with strict inequality, then the contract is in the form $\left(I, K_{0}, D^{\prime}\right)$, where $D^{\prime} \geq V^{L}(I)$. In addition, $R=I$, for otherwise the incumbent could offer $\left(R+\epsilon, K, D^{\prime}\right)$; if $\epsilon$ (> 0 ) were small, it would still be accepted and would provide him with a payoff higher than $V^{L}(I)$ at $(I, D)$. Similarly, $D^{\prime} \geq V^{L}(f(K))$, for otherwise, by proposition 1 , the incumbent could achieve a higher payoff by offering a contract with a slightly higher next period's debt. ${ }^{21}$ Since $-K+\beta E V^{L}(F(K))$ is strictly increasing

\footnotetext{
${ }^{21}$ More precisely, the lender can offer $\left(R_{2}, K_{2}, D_{2}^{\prime \prime}\right)$, where $D_{2}^{\prime \prime}=D_{2}^{\prime}$ with probability $1-\epsilon$ and $D_{2}^{\prime \prime}>D_{2}^{\prime}$ with probability $\epsilon$. If $\epsilon$ is small, the borrower still strictly prefers this contract to $\left(R, K, D^{\prime}\right)$
} 
on $\left[0, K_{0}\right]$ and strictly decreasing on $\left[K_{0}, \infty\right), K=K_{0}$, for otherwise the incumbent can change $K$ marginally, such that the borrower still accepts the contract. QED

ClaIm 4. $V^{L}(I)=V^{L}(0)+I$ and $V^{L}(0)=-K_{0}+\beta E V^{L}\left(F\left(K_{0}\right)\right)$ if and only if the equilibrium contract at $(I, D)$, where $V^{L}(I) \geq D$, is $\left(I, K_{0}, D^{\prime}\right)$, where $D^{\prime} \geq$ $V^{L}\left(f\left(K_{0}\right)\right)$.

Proof. Suppose that $V^{L}(I)=V^{L}(0)+I$ and $V^{L}(0)=-K_{0}+\beta E V^{L}\left(F\left(K_{0}\right)\right)$. Let $\left(R^{*}, K^{*}, D^{*}\right)$ denote the equilibrium contract at $(I, D)$. Then $\left(0, K^{*}, D^{*}\right)$ would be accepted by the borrower at $(0, D)$ and provide the lender with a payoff $V^{L}(I)-R^{*} \geq V^{L}(I)-I=V^{L}(0)$. But we established in the text that at state $(0$, $D)$ the only contract that provides the lender with a payoff of at least $V^{L}(0)$ is in the form $\left(0, K_{0}, D^{\prime}\right)$, where $D^{\prime} \geq V^{L}\left(f\left(K_{0}\right)\right)$. Hence, $K^{*}=K_{0}$ and $D^{\prime} \geq$ $V^{L}\left(f\left(K_{0}\right)\right)$. In addition, $R^{*}=I$, for otherwise $V^{L}(I)=V^{L}(0)+R^{*}<V^{L}(0)+I$, a contradiction. Conversely, if the equilibrium contract is $\left(I, K_{0}, D^{\prime}\right)$, where $D^{\prime} \geq V^{L}\left(f\left(K_{0}\right)\right)$, then the lender's payoff is obviously $V^{L}(0)+I$, and $V^{L}(0)=$ $-K_{0}+\beta E V^{L}\left(F\left(K_{0}\right)\right)$. QED

\section{Proof of Claim 1}

First, we show that if the equilibrium contract at $(I, D),\left(R^{*}, K^{*}, D^{*}\right)$, does not maximize the borrower's payoff subject to (3) with $D=V^{L}(I)$, then $V^{L}(I)=$ $V^{L}(0)+I$, and $V^{L}(0)=-K_{0}+\beta E V^{L}\left(F\left(K_{0}\right)\right)$. Suppose by contradiction that there is a feasible contract $\left(R_{2}, K_{2}, D_{2}^{\prime}\right)$, satisfying (3) with $D=V^{L}(I)$, and it is strictly preferred by the borrower to $\left(R^{*}, K^{*}, D^{*}\right)$. Then $\left(R_{2}, K_{2}, D_{2}^{\prime}\right)$ satisfies (2) with strict inequality. By claim $3,\left(R_{2}, K_{2}\right)=\left(I, K_{0}\right)$, and $D_{2}^{\prime} \geq V^{L}\left(f\left(K_{0}\right)\right)$. We have shown in the text that $-K_{0}+\beta E V^{L}\left(F\left(K_{0}\right)\right) \geq V^{L}(0)$. Hence, part 2 of lemma 1 implies that $\left(R_{2}, K_{2}, D_{2}^{\prime}\right)$ would provide the incumbent with a payoff of $I+$ $V^{L}(0)=V^{L}(I)$, and $V^{L}(0)=-K_{0}+\beta E V^{L}\left(F\left(K_{0}\right)\right)$.

We are ready to show that the borrower's payoff does not depend on whether the debt is $D_{1}$ or $D_{2}$ along any sequence of realization of the shocks. Suppose that the sequence of realized shocks is $\left(s_{1}, s_{2}, \ldots\right)$. Let $C_{i}^{j}=\left(R_{i}^{j}, K_{i}^{j}, D_{i}^{\prime j}\right)$ denote the equilibrium contract at time $i$ if the economy is at state $\left(I, D_{j}\right)(j=1,2)$ at time 0 . Let $i^{*}$ denote the first time period at which either $C_{i}^{1}$ or $C_{i}^{2}$ is not in the form $\left(s_{i} f\left(K_{0}\right), K_{0}, D^{\prime}\right)$, where $D^{\prime} \geq V^{L}\left(f\left(K_{0}\right)\right)$. (If there is no such $i$, then the borrower never consumes and ends up with the zero payoff in both cases.) Up until time $i^{*}$, the borrower does not consume no matter whether the state at time 0 is $\left(I, D_{1}\right)$ or $\left(I, D_{2}\right)$. Suppose that $C_{i^{*}}^{1}$ is not in the form $\left(s_{i^{*}} f\left(K_{0}\right), K_{0}\right.$, $\left.D^{\prime}\right), D^{\prime} \geq V^{L}\left(f\left(K_{0}\right)\right)$. We consider two cases. Case 1: $C_{i^{*}}^{2}$ is in the form $\left(s_{i^{*}} f\left(K_{0}\right)\right.$, $\left.K_{0}, D^{\prime}\right), D^{\prime} \geq V^{L}\left(f\left(K_{0}\right)\right)$. Case 2: $C_{i^{*}}^{2}$ is not in this form. In case 1, from claim 4 it follows that $V^{L}\left(s_{i^{*}} f\left(K_{0}\right)\right)=V^{L}(0)+s_{i^{*}} f\left(K_{0}\right)$ and that $C_{i^{*}}^{1}$ must be in the form $\left(s_{i^{*}-1} f\left(K_{0}\right), K_{0}, D^{\prime}\right), D^{\prime} \geq V^{L}\left(f\left(K_{0}\right)\right)$, a contradiction. In case 2 , both $C_{i^{*}}^{1}$ and $C_{i^{*}}^{2}$ maximize the borrower's payoff subject to (3) with $D=V^{L}\left(s_{i^{*}-1} f\left(K_{0}\right)\right)$. Hence, the borrower's continuation value is the same no matter whether the debt was $D_{1}$ or $D_{2}$ at time 0 . QED

Proof of Claim 2

$a$. If the borrower rejects all contracts at $\left(I, V^{L}(I)\right)$, her payoff would be $I+$ $\beta W\left(0, V^{L}(I) / \beta\right)$. Since $V^{L}(I) / \beta>V^{L}(I) \geq V^{L}(0), W^{B}\left(0, V^{L}(I) / \beta\right)=V^{B}(0)$. Therefore, $I+\beta W\left(0, V^{L}(I) / \beta\right)=I+\beta V^{B}(0)$.

$b$. Since $V^{B}(0)>\beta V^{B}(0)$, the borrower's incentive constraint does not bind at 
$\left(0, V^{L}(0)\right)$. Hence, the equilibrium contract at $\left(0, V^{L}(0)\right)$ satisfies the hypothesis of claim 3 , and therefore it is $\left(0, K_{0}, V^{L}\left(f\left(K_{0}\right)\right)\right)$. QED

Proof of Lemma 2

Suppose first that $I<(1-\beta) V^{B}(0)$. Notice that the contract $\left(I, K_{0}, V^{L}\left(f\left(K_{0}\right)\right)\right)$ provides the borrower with a payoff of $V^{B}(0)>I+\beta V^{B}(0)$ and the lender with a payoff of $V^{L}(0)+I$. Hence, this is the equilibrium contract by claims 2 and 4 .

Suppose now that $I \geq(1-\beta) V^{B}(0)$. Notice that $V^{B}(I) \geq I+\beta V^{B}(0)$, for otherwise the borrower would reject the contract. Suppose by contradiction that $V^{B}(I)>I+\beta V^{B}(0)$. Then by claim 3 the equilibrium contract is $\left(I, K_{0}\right.$, $\left.V^{L}\left(f\left(K_{0}\right)\right)\right)$. But this contract provides the borrower with a payoff of $V^{B}(0) \quad(\leq$ $\left.I+\beta V^{B}(0)\right)$, a contradiction. QED

\section{Proof of Proposition 3}

Notice that whenever $D<V^{L}(I), I^{\prime}$ in (8) is well defined.

First, we show that $W^{B}(I, D) \geq V^{B}\left(I^{\prime}\right)$. Suppose that the equilibrium contract at $\left(I^{\prime}, V^{L}\left(I^{\prime}\right)\right)$ is $\left(R, K, D^{\prime}\right)$, and hence $V^{L}\left(I^{\prime}\right)=R+E\left[-K+\beta W^{L}\left(F(K), D^{\prime}\right)\right]$. Then the contract $\left(R^{\prime}, K, D^{\prime}\right)$, where $R^{\prime}=R-\left(I^{\prime}-I\right)$, satisfies (3) because

$$
R^{\prime}+E\left[-K+\beta W^{L}\left(F(K), D^{\prime}\right)\right]=V^{L}\left(I^{\prime}\right)-\left(I^{\prime}-I\right)=D,
$$

where the last equality follows from (8). Furthermore, since $\left(R, K, D^{\prime}\right)$ was feasible at $\left(I^{\prime}, V^{L}\left(I^{\prime}\right)\right),\left(R^{\prime}, K, D^{\prime}\right)$ is feasible at $(I, D)$. The payoff of the borrower from $\left(R, K, D^{\prime}\right)$ is

$$
I-R^{\prime}+\beta E W^{B}\left(F(K), D^{\prime}\right)=I^{\prime}-R+\beta E W^{B}\left(F(K), D^{\prime}\right)=V^{B}\left(I^{\prime}\right),
$$

where the last equality follows from $\left(R, K, D^{\prime}\right)$ being the equilibrium contract at $\left(I^{\prime}, V^{L}\left(I^{\prime}\right)\right)$. By proposition 2 , the equilibrium contract at $(I, D)$ maximizes (4) subject to (3), and hence $W^{B}(I, D) \geq V^{B}\left(I^{\prime}\right)$.

It remains to show that $W^{B}(I, D) \leq V^{B}\left(I^{\prime}\right)$. Suppose by contradiction that $W^{B}(I, D)>V^{B}\left(I^{\prime}\right)$ and the equilibrium contract at $(I, D)$ is $\left(R, K, D^{\prime}\right)$. Then $\left(R+\left(I^{\prime}-I\right), K, D^{\prime}\right)$ is feasible and would provide the borrower with a payoff of $W^{B}(I, D)\left(>V^{B}\left(I^{\prime}\right)\right)$ at $\left(I^{\prime}, V^{L}\left(I^{\prime}\right)\right)$. The incumbent's payoff would be

$$
W^{L}(I, D)+\left(I^{\prime}-I\right)=D+\left(I^{\prime}-I\right)=V^{L}\left(I^{\prime}\right)
$$

where the first equality follows from proposition 1 and the second one from (8). Hence, the equilibrium contract at $\left(I^{\prime}, V^{L}\left(I^{\prime}\right)\right)$ does not maximize the borrower's payoff subject to the constraint that the lender has to receive at least $V^{L}\left(I^{\prime}\right)$. From the proof of claim 1 it follows that $R+\left(I^{\prime}-I\right)=I^{\prime}, D^{\prime}=$ $V^{L}(f(K))$, and $K=K_{0}$. But then $W^{B}(I, D)=V^{B}(0) \leq V^{B}\left(I^{\prime}\right)$, a contradiction. QED 
Proof of Lemma 3

From (9) and the derivative rule for inverse functions, it follows that $H^{\prime}(I-$ $D)=V^{B \prime}\left(Q^{-1}(I-D)\right) /\left[Q^{\prime}\left(Q^{-1}(I-D)\right)\right]$. Notice that

$$
\begin{aligned}
Q\left((1-\beta) V^{B}(0)\right) & =(1-\beta) V^{B}(0)-V^{L}\left((1-\beta) V^{B}(0)\right) \\
& =(1-\beta) V^{B}(0)-\left[V^{L}(0)+(1-\beta) V^{B}(0)\right] \\
& =-V^{L}(0) \leq-\left[V^{L}(I)-I\right]<I-D .
\end{aligned}
$$

The second equality follows from $V^{L}(I)=V^{L}(0)+I$ on $\left[0,(1-\beta) V^{B}(0)\right]$, established in the proof of lemma 2 . The weak inequality follows from parts $a$ and $b$ of lemma 1 , and the last inequality follows from $D<V^{L}(I)$. Since $Q$ is increasing, $Q^{-1}(I-D)$ is strictly greater than $V^{B}(0)$. Hence, from lemma 2 we know that $V^{B^{\prime}}\left(Q^{-1}(I-D)\right)=1$. From the definition of $Q$ and $(8), Q^{-1}(I-D)=I^{\prime}$. Therefore, $H^{\prime}(I-D)=1 /\left[1-V^{L^{\prime}}\left(I^{\prime}\right)\right]$. From parts $a$ and $b$ of lemma $1, V^{L \prime} \in[0,1]$, yielding $H^{\prime}(I-D) \geq 1$. The concavity of $V^{L}$ (established in lemma 1) and (10) imply the concavity of $H$. QED

\section{Proof of Lemma 4}

Step 1: $I \leq(1-\beta) V^{B}(0)$. On this interval, $V^{L^{\prime}}(I)=1$ and $R(I)=I$, because the monopolist lender offers the contract $\left(I, K_{0}, V^{L}\left(f\left(K_{0}\right)\right)\right)$, as we argued in the proof of lemma 2. This contract provides the incumbent with a payoff of $V^{L}(0)+I$.

Step 2: $I \in\left((1-\beta) V^{B}(0), \infty\right)$. We show that $V^{L}(I)<V^{L}\left((1-\beta) V^{B}(0)\right)+I-$ $(1-\beta) V^{B}(0)$. The weak inequality follows from part $b$ of lemma 1 . Suppose by contradiction that $V^{L}(I)=V^{L}\left((1-\beta) V^{B}(0)\right)+I-(1-\beta) V^{B}(0)$. By step 1 , $V^{L}\left((1-\beta) V^{B}(0)\right)=V^{L}(0)+(1-\beta) V^{B}(0)$. Thus $V^{L}(I)=V^{L}(0)+I$. From claims 2 and 4 it follows that the equilibrium contract is $\left(I, K_{0}, f\left(K_{0}\right)\right)$. But this would provide the borrower with a payoff of $V^{B}(0)<I+\beta V^{B}(0)$, a contradiction. Since $V^{L}$ is concave,

$$
V^{L^{\prime}}(I) \leq \frac{V^{L}(I)-V^{L}\left((1-\beta) V^{B}(0)\right)}{I-(1-\beta) V^{B}(0)}<1
$$

on $\left((1-\beta) V^{B}(0), \infty\right)$.

Step 3: $I \in\left[I_{M}, \infty\right)$. Suppose now that the borrower has so large an income that $R<I$. Such an $I$ exists since $\lim _{K \rightarrow \infty} f^{\prime}(K)=0$. Notice that $D^{\prime}=0$ can be assumed since $H^{\prime} \geq 1$ (as explained in the text before the statement of this lemma). Then the monopolist maximizes $R-E K$ subject to $R=$ $\beta \int_{0}^{1} H(s f(K)) d G(s)-\beta V^{B}(0)$. When we plug the constraint into the maximand, the problem becomes $\max _{K} \beta \int_{0}^{1} H(s f(K)) d G(s)-\beta V^{B}(0)-E K$. The unique solution to this problem is $K_{M}$ defined by (11). Therefore, the unique equilibrium contract is $\left(I_{M}, K_{M}, \quad 0\right)$ whenever $I \geq I_{M}$. (Since $I_{M}+\beta V^{B}(0)=$ $\beta \int_{0}^{1} H\left(s f\left(K_{M}\right)\right) d G(s)$, this contract satisfies the borrower's incentive constraint.) This shows that $V^{L}(I)=I_{M}-K_{M}$ whenever $I \geq I_{M}$, and hence $V^{L \prime}=0$.

Step 4: $I \in\left[0, I_{M}\right)$. Next, we show that if $I<I_{M}$, then $V^{L}\left(I_{M}\right)>V^{L}(I)$. Suppose by contradiction that $V^{L}(I)=V^{L}\left(I_{M}\right)$ and $I<I_{M}$. Then the contract accepted at $I$ must also solve (5) subject to (2) at $\left(I_{M}, V^{L}\left(I_{M}\right)\right)$. Also notice that this contract must specify $R \leq I<I_{M}$. But the solution to (5) subject to (2) at $\left(I_{M}, V^{L}\left(I_{M}\right)\right)$ was shown to be unique, with $R=I_{M}$, a contradiction. The concavity of $V^{L}$ implies that $V^{L \prime} \geq\left[V^{L}\left(I_{M}\right)-V^{L}(I)\right] /\left(I_{M}-I\right)>0$ on $\left[0, I_{M}\right)$. 
Since $V^{L \prime}(I)<1$ if $I>(1-\beta) V^{B}(0)$ by step 2 and $V^{L \prime}>0$ on $\left[0, I_{M}\right)$ by step 4 , it follows that $V^{L^{\prime}}(I) \in(0,1)$ whenever $I \in\left((1-\beta) V^{B}(0), I_{M}\right)$.

Recall that $H(I-D)=V^{B}\left(I^{\prime}\right)=I^{\prime}+\beta V^{B}(0)$, where $I^{\prime}-V^{L}\left(I^{\prime}\right)=I-D$. From steps 1 and 2 and (10) it follows that $H^{\prime}(I-D)>1$ if $H(I-D)<I_{M}+\beta V^{B}(0)$.

It remains to show that $H^{\prime}(0)>1$. Notice that $H(0)=I^{*}+\beta V^{B}(0)$, where $I^{*}$ is defined by $V^{L}\left(I^{*}\right)=I^{*}$. (Since $V^{L}$ is concave, $V^{L}(0)>0$, and $V^{L^{\prime}}(I)=0$ if $I>I_{M}, I^{*}$ is well defined.) From the previous paragraph we know that $H^{\prime}(x)>$ 1 if $H(x)<I_{M}+\beta V^{B}(0)$. Therefore, it is enough to show that $I^{*}<I_{M}$. In step 3, we showed that $V^{L}\left(I_{M}\right)=I_{M}-K_{M}>I_{M}$. Since $V^{L}(I)-I$ is decreasing (by $V^{L \prime} \leq$ 1), it follows that $I^{*}<I_{M}$. QED

\section{Proof of Remark 1}

In step 1 of the proof of lemma 4 we have shown that $R(I)=I$ whenever $I \leq$ $(1-\beta) V^{B}(0)$. Suppose that $I \in\left((1-\beta) V^{B}(0), I_{M}\right)$ and the equilibrium contract is $\left(R, K, D^{\prime}\right)$, where $R<I$. Then the same contract must also solve (5) subject to (2) at $\left(R, V^{L}(R)\right)$. The reason is that $\left(R, K, D^{\prime}\right)$ is obviously feasible and satisfies (2) at $\left(R, V^{L}(R)\right)$. Hence, $V^{L}(I)=V^{L}(R)$. Since $V^{L}$ is increasing by part 1 of lemma 1 , this implies that $V^{L^{\prime}}=0$ on $(R, I)$. This contradicts $V^{L^{\prime}}(I)>0$ on $\left[(1-\beta) V^{B}(0), I_{M}\right]$ established in lemma 4 . In step 3 of the proof of lemma 4 we have also shown that $R(I)=I_{M}$ if $I \geq I_{M}$. QED

\section{Proof of Theorem 3}

a. Suppose by contradiction that the monopolist lender offers a sequence of contracts that provides him with monopoly power forever. The borrower's consumption must sometimes be positive, for otherwise she would choose to default. Therefore, with probability one there is a date at which a contract of the following form is accepted: $\left(R, K, D^{\prime}\right)$ such that $R<I$ and $D^{\prime}=V^{L}(f(K))$. If $I \leq$ $I_{M}$, then $R(I)=I$ by remark 1 , a contradiction. If $I \geq I_{M}$, then the unique equilibrium contract is $\left(I_{M}, K_{M}, 0\right)$ (established in the proof of lemma 4). This contradicts $D^{\prime}=V^{L}(f(K))$.

$b$. First, we show that there exists an $\epsilon>0$ such that whenever $D<V^{L}(I)$, in the equilibrium contract $E K>\epsilon$. Suppose by contradiction that there exists a sequence $\left(I_{n}, D_{n}\right)\left(D_{n}<V^{L}\left(I_{n}\right)\right)$ such that, in the corresponding contracts $\left(R_{n}\right.$, $\left.K_{n}, D_{n}^{\prime}\right), \lim _{n \rightarrow \infty} E K_{n}=0$. Notice that $R_{n}, I_{n} \leq I_{M}$ can be assumed and $E D_{n}, E D_{n}^{\prime} \leq$ $V^{L}\left(I_{M}\right)$, and therefore there is a subsequence of $(n),\left(n_{k}\right)$, such that $\lim _{n_{l} \rightarrow \infty} I_{n_{k}}=I^{*}, \lim _{n_{l} \rightarrow \infty} E D_{n_{k}}=E D^{*}, \lim _{n_{l} \rightarrow \infty} R_{n_{k}}=R^{*}$, and $\lim _{n_{l} \rightarrow \infty} E D_{n_{k}}^{\prime}=E D^{* \prime}$. Then the contract $\left(R^{*}, 0, D^{*}\right)$ is optimal at $\left(I^{*}, D^{*}\right)$ by continuity. (We do not claim that it is actually the equilibrium contract, but it must be payoff equivalent.) If there is no investment ever after acceptance of the contract $\left(R^{*}, 0, D^{* \prime}\right)$, then autarky would be an equilibrium, a contradiction. Let $t$ be the first date at which there is a contract $\left(0, K_{2}, D_{2}^{\prime}\right)$ accepted such that $E K_{2}>0$. We show that the contract $\left(R^{*}, K_{2}, D_{2}^{\prime}\right)$ is strictly preferred by the borrower to $\left(R^{*}, 0, D^{*^{\prime}}\right)$ and satisfies $(3)$ at $\left(I^{*}, D^{*}\right)$. Hence, by proposition 2 , it cannot be payoff equivalent to the equilibrium contract. The borrower's payoff is

$$
I^{*}-R^{*}+\beta^{t+1} E W^{B}\left(F\left(K_{2}\right), D_{2}^{\prime}\right)<I^{*}-R^{*}+\beta E W^{B}\left(F\left(K_{2}\right), D_{2}^{\prime}\right),
$$

because $\beta<1$ and $E W^{B}\left(F\left(K_{2}\right), D_{2}^{\prime}\right)>0$. Notice that $E\left[-K_{2}+\beta W^{L}\left(F\left(K_{2}\right), D^{\prime}\right)\right] \geq$ 0 ; otherwise the lender would not offer $\left(0, K_{2}, D_{2}^{\prime}\right)$ at time $t$. The lender's payoff is 


$$
R^{*}+\beta^{t} E\left[-K_{2}+\beta W^{L}\left(F\left(K_{2}\right), D^{\prime}\right)\right] \leq R^{*}+E\left[-K_{2}+\beta W^{L}\left(F\left(K_{2}\right), D^{\prime}\right)\right] .
$$

Choose $\delta=\min \{\epsilon /[2 f(\bar{K})], 1\}$, where $\bar{K}$ denotes the largest equilibrium investment. Hence the borrower's income is less than $\epsilon / 2$ at least with probability $G(\delta)$ in every period. But since the investment is larger than $\epsilon$, the debt increases by at least $\epsilon / 2$ in such periods if there was no debt overhang. The reason is that if the debt is $D$ in the current period and $D^{\prime}$ in the next one,

$$
D=R-K+\beta E W^{L}\left(F(K), D^{\prime}\right)<\frac{\epsilon}{2}-\epsilon+D^{\prime},
$$

and hence $D^{\prime}-D>\epsilon / 2$. Therefore, with the probability of at least $\delta^{n}$, the debt becomes larger than $n \epsilon / 2$ after $n$ periods (because the shocks are independently distributed across periods). Fix $n$ such that $n \epsilon / 2>V^{L}\left(I_{M}\right)$. Then no matter what the current state $(I, D)$ is, with a probability of at least $G^{n}(\delta)$, the borrower faces debt overhang $n$ periods later. Since there are infinitely many periods, the borrower faces debt overhang with probability one. QED

\section{Appendix B}

\section{The Fixed-Point Theorem}

We have not yet shown that a Markov equilibrium exists in our game. We argue that it is enough to characterize $V^{L}$ because all the other value functions can be expressed in terms of $V^{L}$. Proposition 1 delivers $W^{L}$ as a function of $V^{L}$. By claim 2 and lemma $2, V^{B}(0)$ is defined by the following equation:

$$
V^{B}(0)=\beta G\left(\frac{(1-\beta) V^{B}(0)}{f\left(K_{0}\right)}\right) V^{B}(0)+\beta \int_{(1-\beta) V^{B}(0) / f\left(K_{0}\right)}^{1}\left[s f\left(K_{0}\right)+\beta V^{B}(0)\right] d G(s),
$$

where $K_{0}$ is defined by (7). Equations (7) and (B1) and lemma 2 enable one to determine $V^{B}$ as a function of $V^{L}$. Finally, proposition 3 delivers $W^{B}$ in terms of $V^{L}$ and $V^{B}$.

Recall that $V^{L}(I)$ is the value of the following constrained maximization problem:

$$
\begin{aligned}
& \max _{R, K, D^{\prime}} R+E\left[-K+\beta E W^{L}\left(F(K), D^{\prime}\right)\right] \\
& \text { subject to } I-R+\beta E W^{B}\left(F(K), D^{\prime}\right) \geq I+\beta V^{B}(0), \quad I \geq R .
\end{aligned}
$$

This may seem to be a standard dynamic programming problem. However, the constraint, in particular $W^{B}$, is also influenced by $V^{L}$. As a result, Blackwell's conditions fail to hold for the corresponding fixed-point operator. The operator is nonmonotonic. Hence, we cannot use the usual techniques to guarantee existence and were unable to establish uniqueness.

The argument of the existence proof is as follows. First, we show that the potential candidates for $V^{L}$ are contained in a convex compact set, called $\Gamma$. Then we construct a fixed-point operator, $T$, as follows. For each element of $\Gamma$, say $g$, using proposition $1,(7)$, (B1), lemma 2, and proposition 3 , we construct the rest of the value functions- $V_{g}^{B}, W_{g}^{L}$, and $W_{g}^{B}$-as if $g$ were the true $V^{L}$. Then we define $\operatorname{Tg}(I)$ as the value to the monopolistic lender solving a maximization problem if the borrower's income is $I$, assuming that the value functions are 
$W_{g}^{L}$ and $W_{g}^{B}$. Finally, we show that this operator has a fixed point, and any fixed point determines an equilibrium.

First, notice that $0 \leq W^{B}(I, D)$ and $W^{L}(I, D) \leq S_{\mathrm{FB}}(I)$. Next, we define the set of possible candidates for $V^{L}-V^{L}(0)$. Consider the following set of functions:

$$
\begin{aligned}
\Gamma=\left\{g \mid g \in C[0, \infty), g(0)=0, g \text { is concave, } \forall x, y: \frac{g(x)-g(y)}{x-y} \in[0,1],\right. \\
\left.\frac{d g}{d x}=0 \text { on }\left[S_{\mathrm{FB}}(0), \infty\right)\right\} .
\end{aligned}
$$

From lemma 1 we know that $V^{L}$ is increasing and concave, with slope less than one. If $I \geq S_{\mathrm{FB}}(0)$, then the monopolistic lender is clearly unable to offer a contract that specifies $R=I$, because the discounted present value from a contract cannot exceed $S_{\mathrm{FB}}(0)$. Therefore, from lemma 4 and remark 1 it follows that $V^{L \prime}=0$ on $\left[S_{\mathrm{FB}}(0), \infty\right)$. Hence, if there exists an equilibrium, $V^{L}-$ $V^{L}(0) \in \Gamma$. Observe that $\Gamma$ with the supremum norm is a convex compact set. We are going to define a fixed-point operator on $\Gamma$, where $\Gamma$ is the set of potential candidates for $V^{L}-V^{L}(0)$.

For all $g \in \Gamma$, let $K_{0}(g)$ be the solution to the maximization problem

$$
\max _{K}-K+\beta \int_{0}^{1} g(s f(K)) d G(s) .
$$

(From [7], $K_{0}(g)$ would be the investment made by the monopolist lender if $g=V^{L}-V^{L}(0)$ and $I=0$.) Since $g$ is concave, $K_{0}(g)$ is well defined. Next, define $V_{g}^{B}(0)$ by

$$
\begin{aligned}
V_{g}^{B}(0)= & \beta G\left(\frac{(1-\beta) V_{g}^{B}(0)}{f\left(K_{0}(g)\right)}\right) V_{g}^{B}(0) \\
& +\beta \int_{(1-\beta) V_{g}^{B}(0) / f\left(K_{0}(g)\right)}^{1}\left[s f\left(K_{0}(g)\right)+\beta V_{g}^{B}(0)\right] d G(s) .
\end{aligned}
$$

Since $\beta<1, V_{g}^{B}(0)$ is well defined. Define $V_{g}^{B}(I)$, the monopolistic value function of the borrower if $g$ were equal to $V^{L}-V^{L}(0)$, by

$$
V_{g}^{B}(I)= \begin{cases}V_{g}^{B}(0) & \text { if } I \leq(1-\beta) V_{g}^{B}(0) \\ I+\beta V_{g}^{B}(0) & \text { otherwise. }\end{cases}
$$

Furthermore, define $V_{g}^{L}(0)$ by the following equation:

$$
V_{g}^{L}(0)=-K_{0}(g)+\beta \int_{0}^{1}\left[V_{g}^{L}(0)+g\left(s f\left(K_{0}(g)\right)\right)\right] d G(s) .
$$

(Clearly, $V_{g}^{L}(0)$ would be $V^{L}(0)$ if $g=V^{L}-V^{L}(0)$.) Define $V_{g}^{L}(I)=V_{g}^{L}(0)+$ $g(I)$. 3:

Let $H_{g}(x)$ be described by the following equations, in the spirit of proposition

$$
H_{g}(x)=V_{g}^{B}\left(I^{\prime}\right),
$$

where $V_{g}^{L}\left(I^{\prime}\right)-I^{\prime}=-x$. Given $V_{g}^{L}$ and $V_{g}^{B}$, one can define $W_{g}^{L}(I, D)$ and $W_{g}^{B}(I$, 
$D)$ by $W_{g}^{L}(I, D)=\min \left\{D, V_{g}^{L}(I)\right\}$ and

$$
W_{g}^{B}(I, D)= \begin{cases}H_{g}(I-D) & \text { if } D<V_{g}^{L}(I) \\ V_{g}^{B}(I) & \text { if } D \geq V_{g}^{L}(I) .\end{cases}
$$

Define the operator $T_{0}: \Gamma \rightarrow C([0, S(0)])$ as follows. Let $T_{0} g(I)$ be the value of the maximization problem

$$
\max _{R, K, D^{\prime}}-K+R+\beta \int_{0}^{1} W_{g}^{L}\left(s f(K), D^{\prime}\right) d G(s)
$$

subject to

$$
R=\min \left\{I, \beta \int_{0}^{1} W_{g}^{B}\left(s f(K), D^{\prime}\right) d G(s)-\beta V_{g}^{B}(0)\right\} .
$$

Notice that $T_{0} g(I)$ would be the value to the monopolistic lender if the value functions were $W_{g}^{L}$ and $W_{g}^{B}$ and he could use only deterministic contracts. For some values of income, the lender might be better off randomizing between optimal deterministic contracts at different income levels such that (B3) is satisfied in expectation. Hence, to find the generated value function of the lender, one must consider the convex hull of $T_{0} g$. Define the fixed-point operator $T: \Gamma \rightarrow \Gamma$ as follows:

$$
\operatorname{Tg}=\operatorname{conc}\left(T_{0} g\right)-\left[\operatorname{conc}\left(T_{0} g\right)\right](0),
$$

where conc denotes the concavification of a function. To see that $T$ indeed maps into $\Gamma$, one can show that $T g$ is continuous and concave with slope less than one and that $(T g)(0)=0$. The concavity of $T g$ and $(T g)(0)=0$ follow immediately from the construction. The continuity of $T g$ and the fact that its slope is less than one follow from the proof of lemma 1.

Proposition 4.

a. The operator $T$ has a fixed point.

$b$. There is a bijection between fixed points and Markov equilibria.

c. Autarky is not a Markov equilibrium.

Proof. $\quad a$. We apply Schauder's fixed-point theorem to the operator $T$. As we mentioned, the set $\Gamma$ is a convex compact set. It remains to show that the operator $T$ is continuous with respect to the supremum norm. This would clearly follow from the continuity of $T_{0}$. Notice that the functionals $K_{0}(g), V_{g}^{B}(0), V_{g}^{L}(0), H_{g}$, $W_{g}^{L}$, and $W_{g}^{B}$ are all continuous in $g$. Therefore, the maximand in (B2) and the constraint (B3) are both continuous. Thus $T_{0}$ is a continuous operator.

$b$. If $g=V^{L}-V^{L}(0)$, where $V^{L}$ is an equilibrium value function of the lender, then $g$ is obviously a fixed point of $T$. If $g$ is a fixed point of $T$, then it follows from the proof of theorem 9.2 in Stokey and Lucas (1989) that $V^{L}$, where $V^{L}-V^{L}(0)=g$, corresponds to an equilibrium.

c. Suppose, to the contrary, that autarky is a Markov equilibrium. This would mean that there is an equilibrium in which $V^{L} \equiv 0$ and that $g \equiv 0$ is a fixed point of $T$, by part 2 of this proposition. To get a contradiction, we show that $\left(T_{0} g\right)(I)>0$ whenever $I$ is large enough, in particular if $I \geq \beta \int_{0}^{1} s f\left(K_{\mathrm{FB}}\right) d G(s)$. If $g \equiv 0$, then $K_{0}(g)=0, W_{g}^{L} \equiv 0$, and $V_{g}^{B}(I)=W_{g}^{B}(I, D)=I$. Then (B2) and (B3) become 


$$
\begin{aligned}
& \max _{R, K, D^{\prime}}-K+R \\
& \text { subject to } R=\min \left\{I, \beta \int_{0}^{1} s f(K) d G(s)\right\} .
\end{aligned}
$$

If $I$ is large enough, $R=\beta \int_{0}^{1} s f(K) d G(s)$, and the maximization problem can be rewritten as $\max _{K}-K+\beta \int_{0}^{1} s f(K) d G(s)$. The solution is clearly $K_{\mathrm{FB}}$, and the feasibility constraint is indeed satisfied if $I \geq \beta \int_{0}^{1} s f\left(K_{\mathrm{FB}}\right) d G(s)$. Therefore, $\left(T_{0} g\right)(I)=-K_{\mathrm{FB}}+\beta \int_{0}^{1} s f\left(K_{\mathrm{FB}}\right) d G(s)>0$. QED

\section{References}

Aguiar, Mark, and Gita Gopinath. 2006. "Defaultable Debt, Interest Rates and the Current Account." J. Internat. Econ. 69 (June): 64-83.

. 2007. "Emerging Market Business Cycles: The Cycle Is the Trend." J.P.E. 115 (February): 69-102.

Albuquerque, Rui, and Hugo A. Hopenhayn. 2004. "Optimal Lending Contracts and Firm Dynamics.” Rev. Econ. Studies 71 (April): 285-315.

Arellano, Cristina. 2005. "Default Risk and Aggregate Fluctuations in Emerging Economies." Manuscript, Univ. Minnesota.

Arrau, Patricio. 1990. "How Does the Debt Crisis Affect Investment and Growth?: A Neoclassical Growth Model Applied to Mexico." Working paper, World Bank, Washington, DC.

Arslanalp, Serkan, and Peter Blair Henry. 2005. "Is Debt Relief Efficient?" J. Finance 60 (April): 1017-51.

Atkeson, Andrew. 1991. "International Lending with Moral Hazard and Risk of Repudiation.” Econometrica 59 (July): 1069-89.

Borensztein, Eduardo. 1990a. "Debt Overhang, Credit Rationing and Investment." J. Development Econ. 32 (April): 315-35.

. 1990b. "The Debt Overhang, Debt Reduction and Investment: The Case of the Philippines." Working Paper no. WP/90/77, Internat. Monetary Fund, Washington, DC.

Bulow, Jeremy, and Kenneth Rogoff. 1988. "The Buyback Boondoggle." Brookings Papers Econ. Activity, no. 2: 645-98.

. 1989. “A Constant Recontracting Model of Sovereign Debt.” J.P.E. 97 (February): 155-78.

. 1991. "Sovereign Debt Repurchases: No Cure for Overhang." Q.J.E. 106 (November): 1219-35.

Calvo, Guillermo A., and Graciela L. Kaminsky. 1991. "Debt Relief and Debt Rescheduling: The Optimal-Contract Approach.” J. Development Econ. 36 (July): 5-36.

Chuhan, Punam, and Federico Sturzenegger. 2005. "Default Episodes in the 1980s and 1990s: What Have We Learned?" In Managing Economic Volatility and Crises: A Practitioner's Guide, edited by Joshua Aizenman and Brian Pinto. New York: Cambridge Univ. Press.

Clementi, Gian Luca, and Hugo A. Hopenhayn. 2006. "A Theory of Financing Constraints and Firm Dynamics." Q.J.E. 121 (February): 229-65.

Cline, William R. 1995. International Debt Reexamined. Washington, DC: Inst. Internat. Econ.

Cline, William R., and Kevin S. Barnes. 1997. "Spreads and Risk in Emerging 
Market Lending.” Research Paper no. 97-1, Inst. Internat. Econ., Washington, DC.

Cole, Harold, James Dow, and William B. English. 1995. "Default, Settlement, and Signalling: Lending Resumption in a Reputational Model of Sovereign Debt." Internat. Econ. Rev. 36 (May): 365-85.

Deshpande, Ashwini. 1997. "The Debt Overhang and the Disincentive to Invest." J. Development Econ. 52 (February): 169-87.

Eaton, Jonathan, and Mark Gersovitz. 1981. "Debt with Potential Repudiation: Theoretical and Empirical Analysis." Rev. Econ. Studies 48 (April): 289-309.

Edwards, Sebastian. 1984. "LDC Foreign Borrowing and Default Risk: An Empirical Investigation, 1976-80.” A.E.R. 74 (September): 726-34.

. 1986. "The Pricing of Bonds and Bank Loans in International Markets: An Empirical Analysis of Developing Countries' Foreign Borrowing." European Econ. Rev. 30 (June): 565-89.

Fama, Eugene F., and Merton H. Miller. 1972. The Theory of Finance. New York: Holt, Rinehart and Winston.

Fernandez, Raquel, and Robert W. Rosenthal. 1990. "Strategic Models of Sovereign-Debt Renegotiations." Rev. Econ. Studies 57 (July): 331-49.

Fischer, Stanley. 1987 "Sharing the Burden of the International Debt Crisis." A.E.R. Papers and Proc. 77 (May): 165-70.

Froot, Kenneth A. 1989. "Buybacks, Exit Bonds, and the Optimality of Debt and Liquidity Relief." Internat. Econ. Rev. 30 (February): 49-70.

Fry, Maxwell J. 1989. "Foreign Debt Instability: An Analysis of National Saving and Domestic Investment Responses to Foreign Debt Accumulation in 28 Developing Countries." J. Internat. Money and Finance 8 (September): 315-44.

Greene, Joshua, and Delano Villanueva. 1991. "Private Investment in Developing Countries: An Empirical Analysis.” Internat. Monetary Fund Staff Papers 38 (March): 33-58.

Kletzer, Kenneth M., and Brian D. Wright. 2000. "Sovereign Debt as Intertemporal Barter." A.E.R. 90 (June): 621-39.

Krugman, Paul R. 1988a. "Financing vs. Forgiving a Debt Overhang." J. Development Econ. 29 (November): 253-68.

. 1988b. "Market-Based Debt-Reduction Schemes." Working Paper no. 2587 (November), NBER, Cambridge, MA.

Neumeyer, Pablo A., and Fabrizio Perri. 2005. "Business Cycles in Emerging Economies: The Role of Interest Rates." J. Monetary Econ. 52 (March): 34580 .

Ozler, Sule. 1989. "On the Relation between Reschedulings and Bank Value." A.E.R. 79 (December): 1117-31.

Sachs, Jeffrey D. 1988. "Comprehensive Debt Retirement: The Bolivian Example." Brookings Papers Econ. Activity, no. 2: 705-13.

- 1989. "The Debt Overhang of Developing Countries." In Debt, Stabilization, and Development: Essays in Memory of Carlos Díaz-Alejandro, edited by Guillermo A. Calvo, Ronald Findlay, Pentti Kouri, and Jorge Braga de Macedo. Cambridge, MA: Blackwell.

. 1990. "A Strategy for Efficient Debt Reduction." J. Econ. Perspectives 4 (Winter): 19-29.

Stokey, Nancy L., and Robert E. Lucas Jr. 1989. Recursive Methods in Economic Dynamics. With Edward C. Prescott. Cambridge, MA: Harvard Univ. Press.

Sturzenegger, Federico. 2004. "Tools for the Analysis of Debt Problems." J. Restructuring Finance 1 (March): 201-23.

Sturzenegger, Federico, and Jeromin Zettelmeyer. 2005. "Defaults in the 90s: 
Learning to Deal with Crises.” Manuscript, Univ. Torcuato di Tella, Dean Bus. School, and Internat. Monetary Fund, Washington, DC.

Thomas, Jonathan, and Tim Worrall. 1994. "Foreign Direct Investment and the Risk of Expropriation." Rev. Econ. Studies 61 (January): 81-108.

Uribe, Martin, and Vivian Z. Yue. 2006. "Country Spreads and Emerging Countries: Who Drives Whom?” J. Internat. Econ. 69 (June): 6-36.

Yue, Vivian Z. 2005. "Sovereign Default and Debt Renegotiation." Manuscript, Univ. Pennsylvania. 